\title{
DEVELOPMENT AND DEMONSTRATION OF NOVEL LOW-NOX BURNERS FOR BOILERS IN THE STEEL INDUSTRY
}

FINAL TECHNICAL REPORT

(September 1999 to September 2006)

DOE Award Number DE-FC36-99ID13821

GTI Project Numbers 15306 (61124)

Prepared by:

Gas Technology Institute

1700 South Mount Prospect Road

Des Plaines, Illinois 60018-1804

Principal Investigator

David Cygan, (847) 768-0524

david.cygan@gastechnology.org

\author{
Subcontractors \\ Hamworthy Peabody Combustion, Incorporated \\ (formerly Peabody Engineering Corporation) \\ University of Utah \\ Far West Electrochemical
}

Project Partners

Gas Technology Institute Sustaining Membership Program

Gas Research Institute

Coke Oven Gas Boiler Site 


\section{DOCUMENT AVAILABILITY:}

Reports are available free via the U.S. Department of Energy (DOE) Information Bridge:

Web Site http://www.osti.gov/bridge

Reports are available to DOE employees, DOE contractors, Energy Technology Data Exchange (ETDE) representatives, and Informational Nuclear Information System (INIS) representatives from the following source:

Office of Scientific and Technical Information

P.O. Box 62

Oak Ridge, TN 37831

Tel: (865) 576-8401

Fax: (865) 576-5728

E-mail: reports@osti.gov

Web site: http://www.osti.gov/contract.html 


\section{DISCLAIMER:}

This report was prepared as an account of work supported by the U.S. Department of Energy under Award No. DE-FC36-99ID13821, GRI, and GTI's Sustaining Membership Program.

Neither the U.S. Department of Energy, GRI, GTI, nor any of their employees, contractors, subcontractors, or their employees makes any warranties, expressed or implied, or assumes any legal liability or responsibility for the accuracy, completeness, or usefulness of any information, apparatus, project, or process disclosed, or represents that its use would not infringe privately owned rights.

Reference to trade names or specific commercial products, commodities, or services in this report does not represent or constitute an endorsement, recommendation, or opinion of suitability by the U.S. Department of Energy, GRI, or GTI of the specific commercial product, commodity, or service. 


\section{TABLE OF CONTENTS}

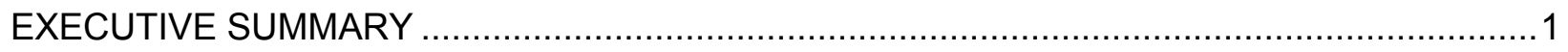

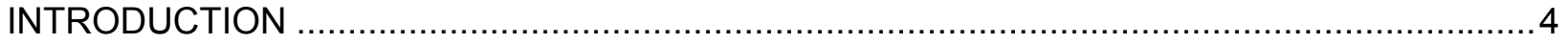

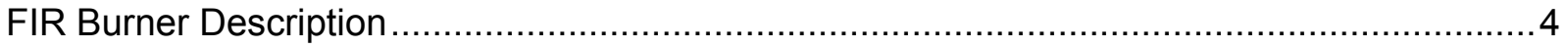

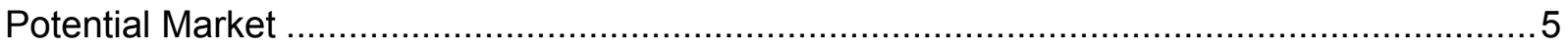

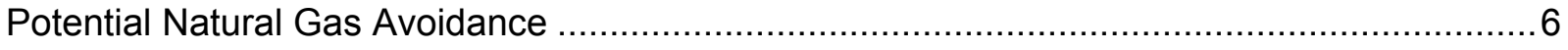

Economic, Energy, and Environmental Benefits ..........................................................

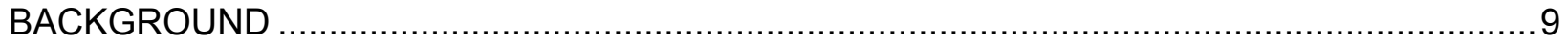

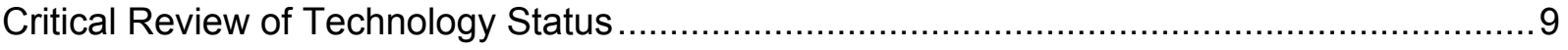

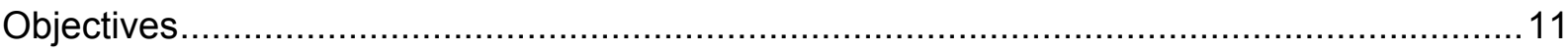

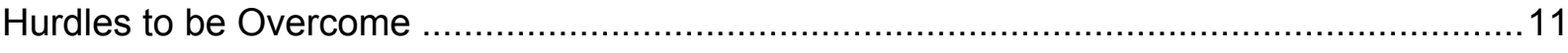

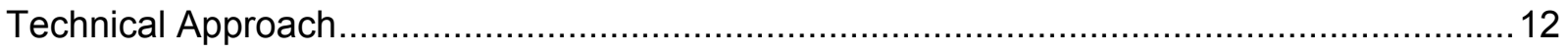

PHASE I - 20 MILLION BTU/H PROTOTYPE BURNER LABORATORY EVALUATION ..........13

20 million Btu/h Watertube Boiler Test Facility .............................................................13

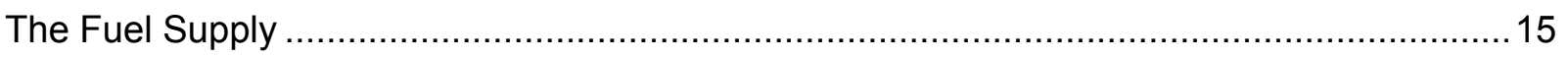

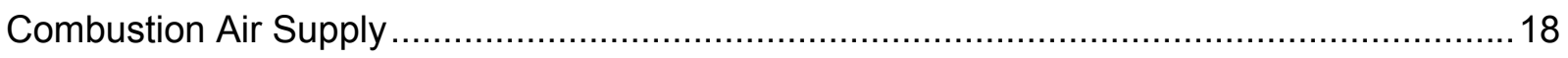

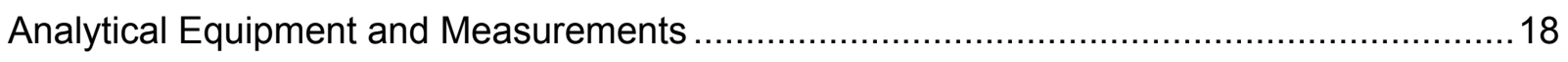

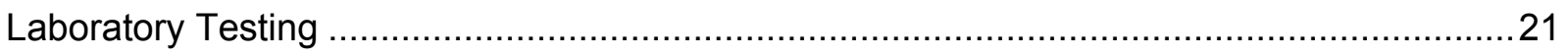

PHASE II - FULL-SCALE FIELD EVALUATION AT COKE-OVEN GAS BOILER SITE ............32

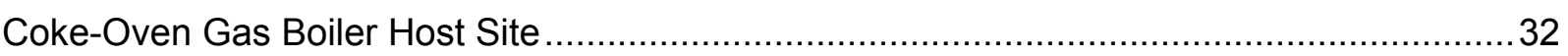

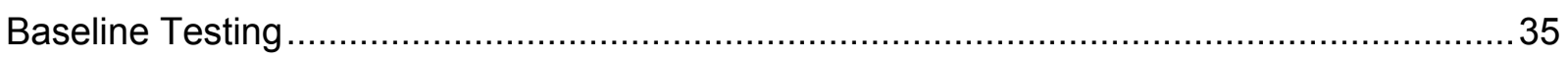

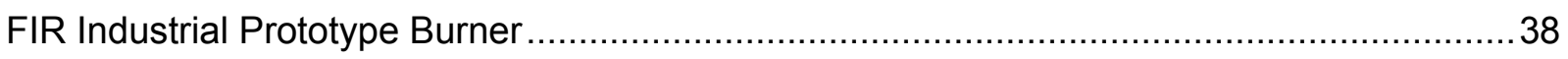

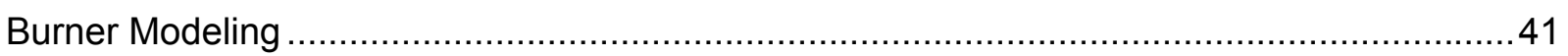

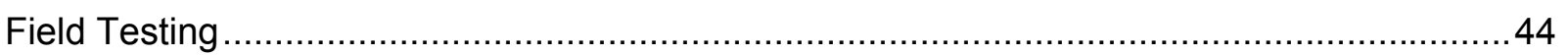

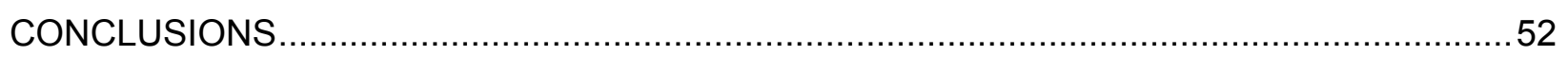

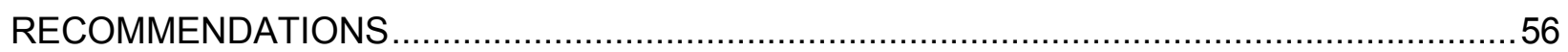

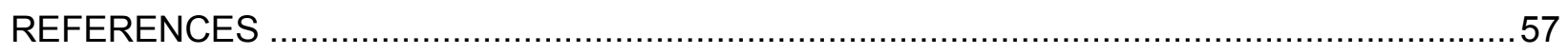

APPENDIX 


\section{LIST OF FIGURES}

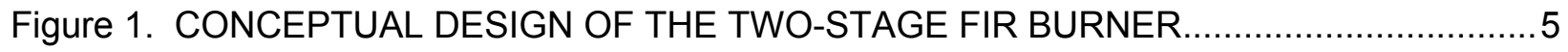

Figure 2. 20 MILLION BTU/H WATERTUBE BOILER TEST FACILITY AT GTI ....................14

Figure 3. ENDOTHERMIC GAS GENERATOR .......................................................... 16

Figure 4. NATURAL GAS AND ENDOTHERMIC GAS MIXER ARRANGEMENT ...................17

Figure 5. GAS SAMPLING FLOW CONTROL AND INSTRUMENTATION........................... 19

Figure 6. SINGLE BURNER PROTOTYPE ARRANGEMENT ........................................23

Figure 7. MULTI-BURNER PROTOTYPE ARRANGEMENT ........................................... 25

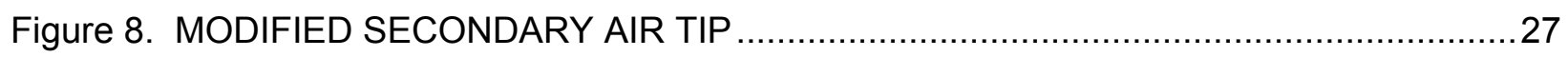

Figure 9. THE EFFECT OF PRIMARY NOZZLE FIRING LOCATION.................................28

Figure 10. NOx FORMATION IS A FUNCTION OF AMMONIA CONCENTRATION ................30

Figure 11. FUEL-FORMED NOx AS A FUNCTION OF AMMONIA CONCENTRATION ..........31

Figure 12. HAMWORTHY PEABODY BURNER AT COKE-OVEN GAS BOILER SITE ...........33

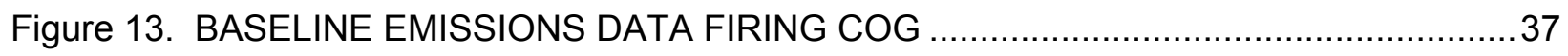

Figure 14. FIR BURNER INSTALLATION AT COKE-OVEN GAS BOILER SITE ...................39

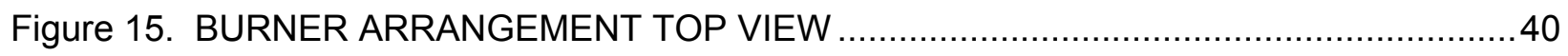

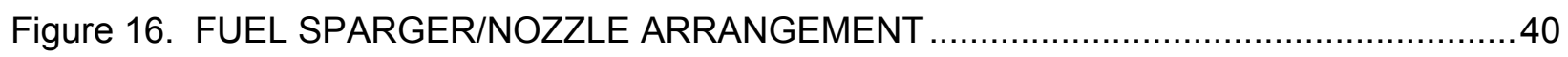

Figure 17. CFD MODEL WITH AND WITHOUT REFRACTORY FLOOR .............................43

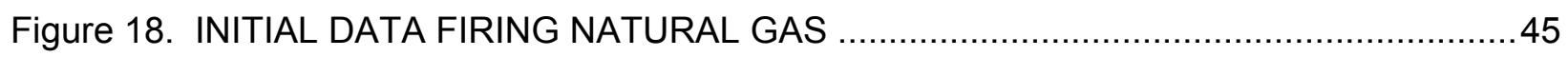

Figure 19. FIR BURNER EMISSIONS FIRING COG SCRUBBER OFF-LINE ......................47

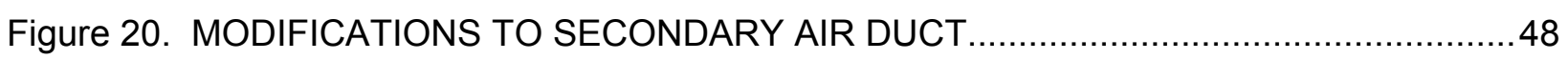

Figure 21. FIR BURNER EMISSIONS FIRING COG SCRUBBER ON-LINE ......................50

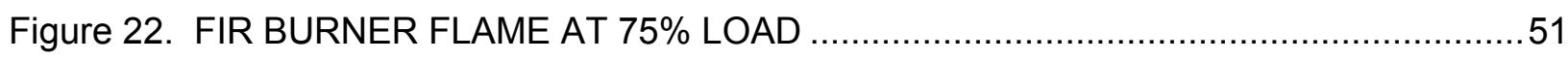

Figure 23. NOX COMPARISON AS IT RELATES TO NITROGEN COMPOUNDS IN COG .....55 


\section{LIST OF TABLES}

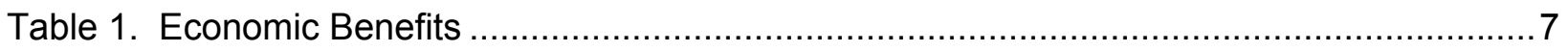

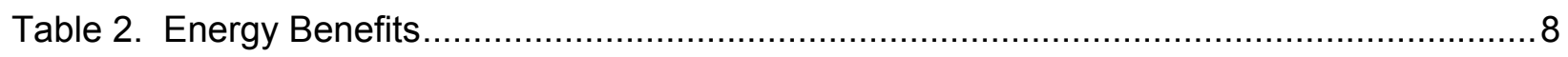

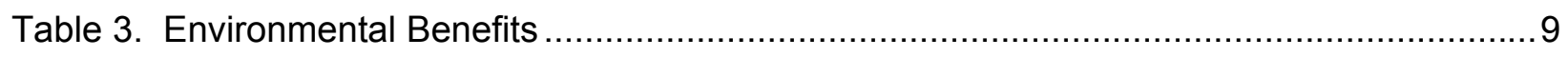

Table 4. Typical Steel Mill Byproduct Gas Compositions ................................................. 10

Table 5. COG Alternative Mixtures ........................................................................ 22

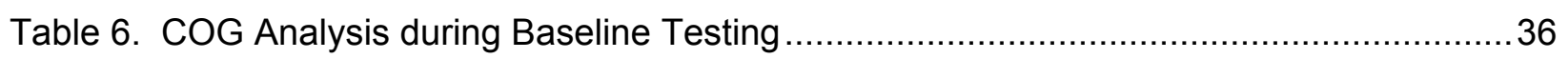

Table 7. Physical Models Used for CFD Calculations .................................................. 41

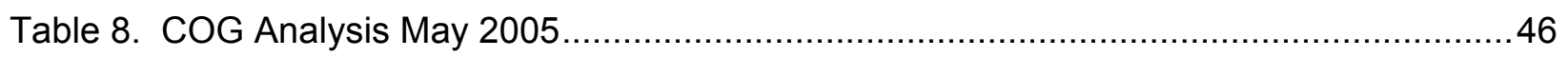

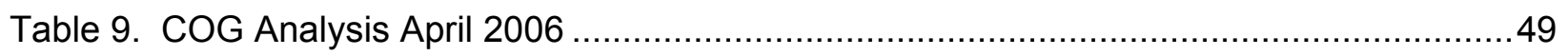

Table 10. Operating U.S. Coke Plants (as of March 18, 2005)..........................................59

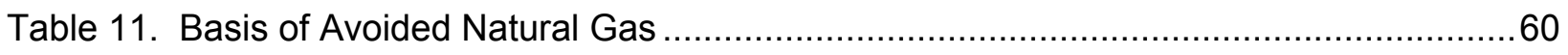

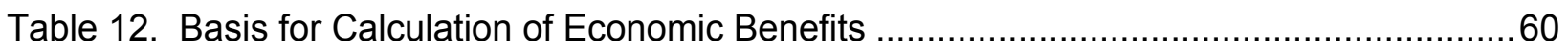

Table 13. Basis for Calculation of Energy Benefits ................................................... 61

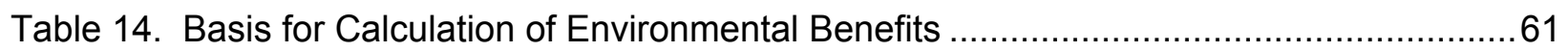




\section{EXECUTIVE SUMMARY}

Gas Technology Institute (GTI), together with Hamworthy Peabody Combustion Incorporated (formerly Peabody Engineering Corporation), the University of Utah, and Far West Electrochemical have developed and demonstrated an innovative combustion system suitable for natural gas and coke-oven gas firing within the steel industry. The combustion system is a simple, low-cost, energy-efficient burner that can reduce NOx by more than $75 \%$. The U.S. steel industry needs to address NOx control at its steelmaking facilities. A significant part of NOx emissions comes from gas-fired boilers. In steel plants, byproduct gases - blast furnace gas (BFG) and coke-oven gas (COG) - are widely used together with natural gas to fire furnaces and boilers.

In steel plants, natural gas can be fired together with BFG and COG, but, typically, the addition of natural gas raises NOx emissions, which can already be high because of residual fuel-bound nitrogen in COG. The Project Team has applied its expertise in low-NOx burners to lower NOx levels for these applications by combining advanced burner geometry and combustion staging with control strategies tailored to mixtures of natural gas and byproduct fuel gases. These methods reduce all varieties of NOx - thermal NOx produced by high flame temperatures, prompt NOx produced by complex chain reactions involving radical hydrocarbon species and NOx from fuel-bound nitrogen compounds such as ammonia found in COG.

The Project Team has expanded GTI's highly successful low-NOx forced internal recirculation (FIR) burner, previously developed for natural gas-fired boilers, into facilities that utilize BFG and COG. For natural gas firing, these burners have been shown to reduce NOx emissions from typical uncontrolled levels of $80-100 \mathrm{vppm}$ to single-digit levels (9 vppm). This is done without the energy efficiency penalties incurred by alternative NOx control methods, such as external flue gas recirculation (FGR), water injection, and selective non-catalytic reduction. The FIR burner was previously demonstrated on firetube and watertube boilers, and these units are still operating at several industrial and commercial boiler sites in sizes ranging from 2.5 to 60 million Btu/h. 
The main goals of the project were to develop and demonstrate a gas-fired burner that can maintain less than $15 \mathrm{vppm} \mathrm{NOx}^{*}$ emissions in steel industry boilers, and, ultimately, to commercialize a family of burners that can meet this performance level without efficiency penalties and at lower cost than available alternative control technologies. These goals are directly responsive to the priorities listed in the U.S. Department of Energy's Steel Industry Technology Roadmap (Section 4.9 Nitrogen Oxides and Steelmaking).

This report covers the development of an innovative combustion system suitable for natural gas or coke-oven gas firing within the steel industry. The prototype FIR burner was evaluated on a 20 million Btu/h watertube boiler. Both single- and multi-burner arrangements were evaluated. The prototype FIR burner has proven to operate satisfactory on the 20 million Btu/h watertube boiler at GTI. Acceptable burner performance was obtained when firing natural gas and simulated coke-oven gas doped with ammonia. The laboratory data reveals a direct relationship between NOx formation and the ammonia concentration in the fuel. In addition, NOx formation increases as the primary stoichiometric ratio (PSR) increases. Representative ammonia concentrations, as documented in the steel industry, ranged from 200 to $500 \mathrm{vppm}$. When the laboratory burner/boiler was operated with $500 \mathrm{vppm}$ ammonia in the fuel, NOx emissions ranged from 50 to $75 \mathrm{vppm}$. This, conservatively, is $75 \%$ less than state-of-the-art burner performance. When the burner is operated with $200 \mathrm{vppm}$ ammonia in the fuel, the corresponding NOx emissions would range from 30 to $45 \mathrm{vppm}, 84 \%$ less than present burner technology.

During field evaluation on a 174 million Btu/h industrial prototype burner both natural gas and actual COG from on-site generation were tested. Despite the elevated hydrogen cyanide and ammonia content in the COG throughout the test program, the FIR burner showed an improvement over baseline emissions. At full load; 167 million Btu/h, NOx emissions were relatively low at $169 \mathrm{vppm}$. This represents a 30\% reduction compared to baseline emissions not accounting for the higher hydrogen cyanide content in the COG. CO emissions remained below $20 \mathrm{vppm}$ and were stable across the firing range. This represents a $68 \%$ reduction compared to baseline $\mathrm{CO}$ emissions. Modifying the main combustion air opposed blade damper with four blades fixed in their closed position would improve low fire emission

\footnotetext{
*All emissions are corrected to $3 \% \mathrm{O}_{2}$.
} 
performance. When firing natural gas, emissions were stable as firing rate increased over the range. At low fire; 45 million Btu/h, NOx emissions where $33 \mathrm{vppm}$ and increased at full load; 144 million Btu/h, to $49 \mathrm{vppm}$. CO emissions fluctuated with the oxygen content and remained below $135 \mathrm{vppm}$ during all tests. The boiler was operated in manual mode and the oxygen content was set by the operator. The boiler's maximum output was not achieved due to a limitation dictated by the host site natural gas supply.

The FIR burner benefits the public by simultaneously addressing the problems of air pollution and energy conservation through a low-NOx combustion technology that does not increase energy consumption. Continuing activities include the negotiation of a license with Hamworthy Peabody Combustion, Incorporated (Hamworthy Peabody) to commercialize the FIR burner for steel industry applications. Hamworthy Peabody is one of the largest U.S. manufacturers of combustion equipment for boilers in the Steel Industry, and has stated their intention to commercialize the FIR burner. 


\section{INTRODUCTION}

The overall objective of this project is to develop and demonstrate a novel low-NOx burner, based on the forced internal recirculation (FIR) concept, that can burn on-site fuel gases in blends with natural gas and achieve NOx emissions below $15 \mathrm{vppm}$ while maintaining carbon monoxide and total hydrocarbons both below $50 \mathrm{vppm}$. This will be achieved through a combination of internal flue gas recirculation, air staging, fuel staging, and combustion control.

A multi-phase effort was pursued with decision points to determine advisability of continuance. This report covers Phases I and II of this work effort. The objectives of each phase are as follows:

Phase I - to design, fabricate, and evaluate a 20 million Btu/h prototype burner for laboratory evaluation

Phase II - to evaluate the performance of an FIR burner under actual operating conditions in a full-scale field test and establish the performance necessary for subsequent commercialization.

\section{FIR Burner Description}

The FIR burner concept was originally developed by GTI for low-NOx natural gas combustion without any degradation in boiler performance. The initial work began as a GTI IR\&D project to prove the novel concept, for which GTI was granted U.S. Patent No. 5,350,293. ${ }^{1}$ The burner design combines two-stage combustion with partially premixed, fuel-rich, first stage gases and forced internal recirculation of products of partial combustion to reduce formation of "thermal NOx" as well as "prompt NOx." The secondary air enters downstream of the primary combustion zone to complete the combustion process. Enhanced internal recirculation maximizes heat transfer to the process fluid surrounding the combustion space and lowers the peak flame temperature (in both the primary and secondary combustion zones).

Figure 1 shows the conceptual design of the FIR burner. Gas partially mixes with the primary air before entering the combustion zone. The velocity of the gas/air mixture through several nozzles is sufficient to create a reduced pressure zone at the base of the primary nozzle exit, which induces flow from the exit of the primary zone. Inside the recirculation insert, the products of partial combustion flow back to the root of the flame, as indicated by the curved arrows. These combustion products contain hydrogen species, which improves combustion 
stability in the primary zone, allowing combustion at relatively low stoichiometric ratios. Combustion at low stoichiometric ratios (fuel-rich) produces less NOx emissions than complete combustion. Secondary air is injected through a pipe, which is located at the center of the burner downstream of the primary zone, to burn out hydrogen, carbon monoxide, and any unburned hydrocarbons. Mixing of the secondary air with the combustion products from the primary zone is critical to the design of a very-low NOx burner. If the gaseous mixture is well mixed, there are no high concentrations of oxygen, which could cause hot spots and generate NOx. The recirculation insert also radiates heat to the cold boiler walls and allows products of partial combustion to cool before flowing to the secondary combustion zone and back to the root of the flame, cooling and stabilizing it.

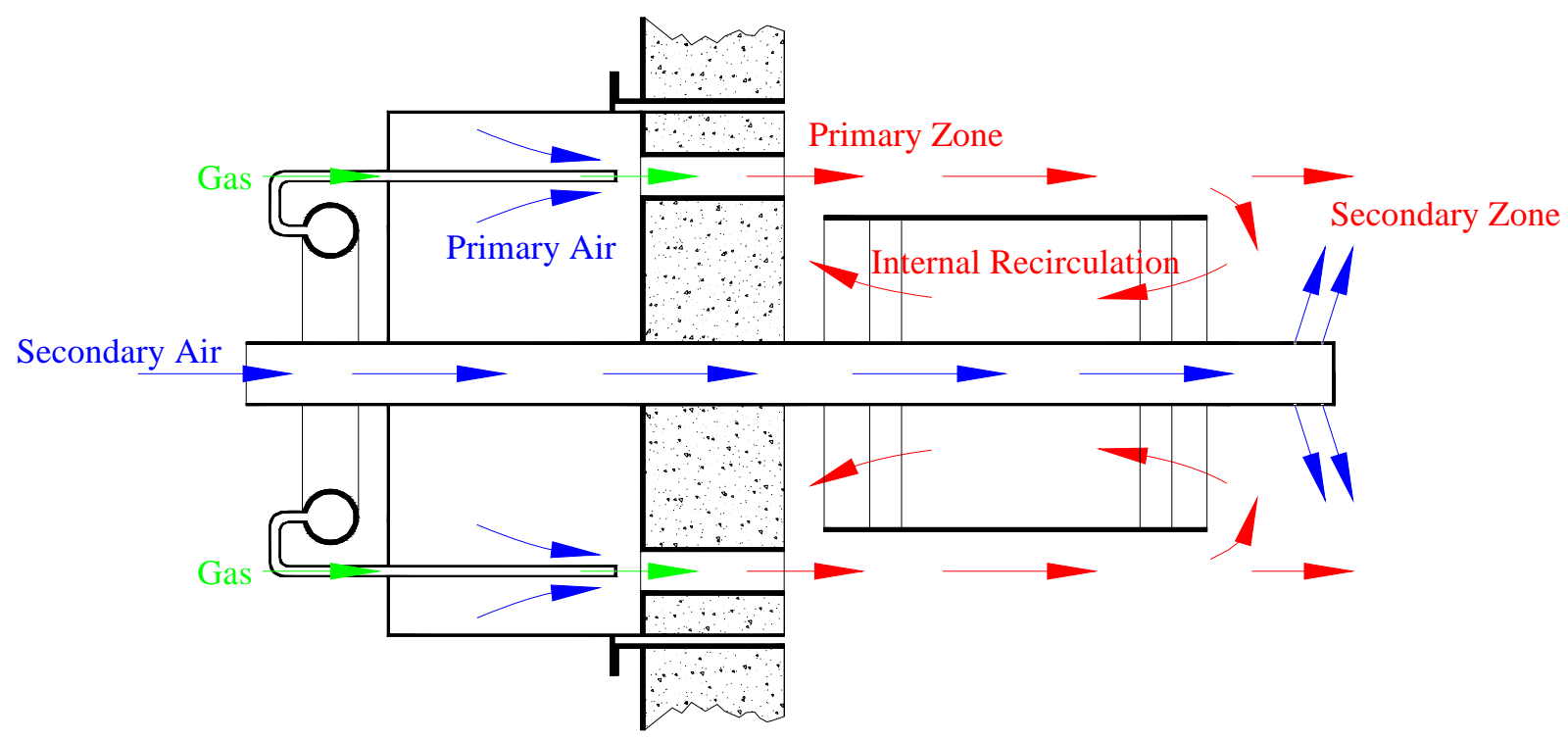

Figure 1. CONCEPTUAL DESIGN OF THE TWO-STAGE FIR BURNER

\section{Potential Market}

The American Coke and Coal Chemicals Institute $(\mathrm{ACCCl})$ is a nonprofit trade association representing producers of metallurgical coke (both furnace and foundry coke); coke sales 
agents; steel manufacturers that produce coke; producers and processors of chemicals derived from the distillation of coal and coal tar; and suppliers to these producers and processors. According to their database, as of March 2005 there are 19 U.S. coke plants ${ }^{2}$ (see Appendix, Table 10) operating 54 coke batteries in 10 states. The Project Team has estimated that there are approximately 250 burners, average size 100 million Btu/h, in this market. Based on October 2003 data $^{3}$, eight of the 15 domestic coke plants represented by $\mathrm{ACCCl}$ are independently owned and operated coke plants that produce coke for sale on the open market. These eight plants, which operate 17 batteries nationwide, produced about 3.5 million tons of coke/year, or about 17.5 percent of the approximately 20 million tons/year of coke produced in the U.S. The seven remaining plants represented by $\mathrm{ACCCl}$ are coke plants operated by integrated steel companies. These plants, which operate 23 batteries nationwide, produce about nine million tons of coke/year, or about 45 percent of the approximately 20 million tons of coke/year produced in the U.S.

\section{Potential Natural Gas Avoidance}

The ability of the FIR burner to achieve low emission levels when firing either natural gas or coke-oven gas is a significant advantage for industrial boiler sites. Coke-oven gas is generally fired because its "free" and "available." However, there are no low-emission burners commercially available for coke-oven gas. Industrial sites will be forced to fire natural gas in the future in order to comply with strict environmental regulations including the New Source Performance Standards and the Ozone particulate transport rule.

Achieving low emissions when firing coke-oven gas with the FIR burner will decrease the dependency on natural gas while maintaining compliance with environmental regulations. The total estimated energy demand from boilers in the steel industry is 219 TBtu/year. A $20 \%$ increase in coke oven gas utilization will result in approximately 44 TBtu/year avoidance of natural gas. A corresponding increase at 5 and $10 \%$ utilization will result in approximately 11 and 22 TBtu/year avoidance of natural gas respectively. These estimates are calculated for all boilers in the steel industry. The basis for avoided natural gas is shown in the Appendix, Table 11. Through discussions with our coke-oven gas boiler site, we confirmed a $5 \%$ increase in coke-oven gas firing is attainable. 


\section{Economic, Energy, and Environmental Benefits}

Economic benefits accrue from the capital and operating costs of the FIR burner system compared to alternative control technologies expected to compete in the future. These alternative control technologies are: 1) external FGR, and 2) selective non-catalytic reduction (SNCR). The basis for calculated benefits is shown in the Appendix, Table 12. The economic benefits are calculated accordingly, for three levels of assumed market penetration.

Table 1. Economic Benefits

\begin{tabular}{|l|l|l|l|}
\hline \multirow{2}{*}{ Annualized cost savings to steel industry compared to: } & \multicolumn{3}{|l|}{ Market penetration } \\
\cline { 3 - 4 } & $10 \%$ & $30 \%$ & $60 \%$ \\
\hline Alternative control method 1, \$million/year & 0.26 & 0.79 & 1.58 \\
Alternative control method 2, \$million/year & 0.40 & 1.21 & 2.43 \\
Combined control methods 1 and 2, \$million/year & 0.74 & 2.21 & 4.42 \\
\hline
\end{tabular}

As shown in Table 1, the FIR burner technology can save the steel industry up to $\$ 1.6$ million per year compared to FGR and up to $\$ 2.4$ million per year compared to SNCR, based on $60 \%$ market penetration. As shown later, this cost saving is also accompanied by a superior emissions performance that is not achievable using either of the alternative technologies alone. Combining FGR and SNCR may be able to match the emissions performance of the burner, but would cost the steel industry up to $\$ 4.4$ million/year more from higher capital and fuel costs.

Energy savings from adoption of the FIR burner technology are realized because this burner operates similar to a standard gas-fired diffusion burner. No added fans or pumps that consume electricity are needed, unlike alternative control technologies. FGR requires an additional fan, and SNCR requires pumps and other energy-consuming hardware. In a boiler, the primary energy loss is in the stack gas, which carries both sensible and latent heat out to the atmosphere. For any given fuel, the energy efficiency can be directly calculated from the stack gas volumetric flow and the stack temperature.

For any given boiler, the use of FGR will increase total mass flux through the system up to the FGR takeoff, and accordingly decrease residence time of hot gases in the furnace and convective pass, and decrease radiative heat transfer because of lower flame emissivity. While 
there is a competing effect from increased convective heat transfer from the higher mass flux, the net effect will generally be an increase in the stack temperature and lower fuel efficiency. ${ }^{4}$ In addition, the use of FGR increases the back pressure and consequently the fan horsepower requirement, which increases electricity cost. Forced FGR requires an additional fan and its associated capital cost. While induced FGR, the preferred method for most manufacturers, does not require a separate fan it does increase the load on the combustion air fan with its consequent energy (and possibly equipment) costs. The basis for calculation of energy benefits is shown in the Appendix, Table 13.

The FIR burner also offers the advantage of a recirculation insert located internal to the combustion chamber. The recirculation insert provides significant radiative heat transfer to the boiler water walls and increases flame emissivity.

The energy benefits are calculated accordingly, for three levels of assumed market penetration. As shown in Table 2, there are significant potential energy savings compared to FGR and SNCR technologies, both of which reduced energy efficiency in boilers. These savings could be as high as 1.3 trillion Btu/year when compared to combined FGR and SNCR which is needed to match the FIR burner in emissions performance.

Table 2. Energy Benefits

\begin{tabular}{|l|l|l|l|}
\hline \multirow{2}{*}{ FIR burner energy savings compared to: } & \multicolumn{3}{|l|}{ Market penetration } \\
\cline { 2 - 4 } & $10 \%$ & $30 \%$ & $60 \%$ \\
\hline Uncontrolled boiler, trillion Btu/year & 0.00 & 0.00 & 0.00 \\
Alternative control method 1, trillion Btu/year & 0.11 & 0.33 & 0.66 \\
Alternative control method 2, trillion Btu/year & 0.11 & 0.33 & 0.66 \\
Combined methods 1 and 2, trillion Btu/year & 0.22 & 0.66 & 1.31 \\
\hline
\end{tabular}

The environmental benefits of this technology are chiefly derived from NOx reductions. Based on current industry information and projections of future advances, the competing technologies, FGR and SNCR, may each be capable of achieving 65\% NOx reduction, from 200 to $70 \mathrm{vppm}$, compared to $15 \mathrm{vppm}$ which is the target of the FIR burner. The Project Team considers that the higher level of NOx reduction is achievable without added complexity in the burner controls 
or any energy penalty, as stated. The basis for calculating environmental benefits is shown in the Appendix, Table 14. The environmental benefits are calculated accordingly:

Table 3. Environmental Benefits

\begin{tabular}{|c|l|l|l|}
\hline \multirow{2}{*}{ NOx emissions benefits from burner compared to: } & \multicolumn{3}{|l|}{ Market penetration } \\
\cline { 2 - 4 } & $10 \%$ & $30 \%$ & $60 \%$ \\
\hline Uncontrolled boiler, ton/year & 1,877 & 5,631 & 11,262 \\
Alternative control method 1, ton/year & 1,594 & 4,783 & 9,566 \\
Alternative control method 2, ton/year & 1,594 & 4,783 & 9,566 \\
\hline
\end{tabular}

As shown in Table 3, the burner compared to no controls, can reduce nationwide NOx emissions from steel plant boilers approximately 11,000 ton/year (assuming 60\% market penetration). Moreover, compared to currently available alternative control technologies, the FIR burner will still save nearly 9,500 ton/year NOx. Combined FGR and SNCR may be able to match the FIR burner technology in emissions performance, but with significantly higher economic costs and energy penalty.

\section{BACKGROUND}

\section{Critical Review of Technology Status}

In the United States, steelmaking facilities use on-site byproduct fuel gases, including blast furnace gas (BFG) and COG, in boilers for steam and power generation. These are low- to medium-Btu fuels on a volume basis, and NOx emissions can be quite high, largely because of fuel-bound nitrogen. Furthermore, because of availability and combustion characteristics, boiler operators often need to co-fire these byproduct gases with natural gas in order to maintain boiler performance.

In typical integrated steel plants, there is a boiler complex associated with the blast furnace operation. BFG produced by the iron-making process, mixed with natural gas, is burned in these boilers to provide steam to air compressor/blowers that, in turn, supply air to the blast furnace. In some mills, a steam turbine also drives a 25 to $75 \mathrm{MW}$ generator. In addition to burning BFG, boilers can burn COG and natural gas. Because the steel industry is energy- 
intensive (15 million Btu/ton steel $)^{5}$, steelmakers are eager to maximize the utilization of their byproduct fuels. Typical BFG and COG compositions are shown in Table 4.

Table 4. Typical Steel Mill Byproduct Gas Compositions

\begin{tabular}{|lll|}
\hline & Blast furnace gas & Coke-oven gas \\
\hline $\mathrm{H}_{2}$, mol\% & 9.0 & 50.0 \\
$\mathrm{CO}$ & 21.0 & 7.0 \\
$\mathrm{CO}_{2}$ & 23.0 & 1.0 \\
$\mathrm{CH}_{4}$ & 0.0 & 35.0 \\
$\mathrm{~N}_{2}$ & 47.0 & 7.0 \\
$\mathrm{NH}_{3}$ & 0.0 & 0.04 \\
\hline Molecular weight & 29.4 & 11.0 \\
$\mathrm{HHV}$, Btu/scf & 96.6 & 538.1 \\
\hline
\end{tabular}

While natural gas can be fired together with BFG and COG in conventional burners, the addition of natural gas may raise flame temperatures and NOx levels, which can already be high due to the hydrogen and residual fuel-bound nitrogen in COG.

Low-NOx burner designs for natural gas firing presumably can be adapted to fire byproduct fuel gases; however, there may be adverse consequences. Nearly all of the currently available lowNOx burners utilize external FGR to lower peak flame temperatures and minimize thermal NOx formation. External FGR not only reduces energy efficiency, but also reduces flame stability. Any variations in byproduct fuel gas composition used in these burners can create serious flame stability problems. The other low-NOx burner technology involves the use of premixed gas and air at elevated excess air levels, fired through a "porous" metal composite. This technology would be susceptible to plugging as well as flashback when using byproduct fuel gases.

The FIR burner technology does not suffer from the above drawbacks. It is a partially premixed staged combustion burner with high levels of hot internal combustion products recirculation, which provides a stable flame at extremely low NOx formation. On natural gas fuel, it operates with $3 \%$ oxygen in the flue gas and has demonstrated less than $9 \mathrm{vppm}$ NOx on a watertube boiler. $^{6}$ 
Other emerging technologies include: dilute oxygen combustion for furnaces, which uses furnace gas as a dilute oxygen source for natural gas fuel; oscillating combustion, which involves the alternating creation of fuel-rich and fuel-lean zones within the flame to reduce peak flame temperatures, and oxygen-enriched air staging, which uses enriched air to achieve lowNOx combustion. These technologies are for high-temperature furnaces and do not appear to be technically or economically viable for boiler applications.

The steel industry worldwide faces many of the same challenges as the domestic steel industry. Many of the overseas facilities are older and thus present more difficult environmental problems, but technological advances are being aggressively pursued in Europe and Japan.

\section{Objectives}

The overall objective of this project is to develop and demonstrate a novel low-NOx burner, based on the FIR concept, that can burn on-site fuel gases or natural gas and achieve NOx emissions below $15 \mathrm{vppm}$ while maintaining both $\mathrm{CO}$ and total hydrocarbons (THC) below $50 \mathrm{vppm}$. This will be achieved through a combination of internal flue gas recirculation, air staging, fuel staging, and combustion control.

\section{Hurdles to be Overcome}

The technical barriers to success are tied to the achievement of complete combustion at low excess air while maintaining adequate NOx control at across-the-board turndown for each fuel. Some of the anticipated challenges are enumerated below:

- Maintenance of flame stability with varying fuel gas composition and consequent variations in calorific value;

- Destruction of NOx precursors generated by fuel-bound nitrogen (e.g., hydrogen cyanide and ammonia) in coke-oven gas; this will be achieved by staging, which must be reconciled with the need for complete combustion in the available boiler combustion chamber.

- Maintaining design and control simplicity and low cost while achieving flexibility of fuel composition and boiler operation.

- Scale-up of the burner from 20 million Btu/h to demonstration scale, 174 million Btu/h. 


\section{Technical Approach}

The technical approach was a multi-step process that included evaluation of a prototype FIR burner at GTI's Applied Combustion Research Laboratory; locating a suitable host site; baseline testing at the host site; design, manufacture, and installation of an industrial prototype FIR burner; and performance testing.

The first part of the project was to evaluate a prototype FIR burner firing natural gas, simulated COG, and simulated COG doped with ammonia on a 20 million Btu/h watertube boiler at GTI. Hamworthy Peabody manufactured the prototype FIR burner. Testing on natural gas was straightforward. However, COG was not readily available, therefore a mixture of natural gas and endothermic gas in proportions that closely matched the Wobbe index of COG was used. Additional tests were conducted with simulated COG doped with ammonia. The added ammonia content was representative of fuel compositions found within the steel industry. Representative ammonia concentrations, as documented in the steel industry, ranged from 200 to $500 \mathrm{vppm}$. Ammonia concentrations were varied in the laboratory evaluation from zero to $1000 \mathrm{vppm}$, clearly extending the range encountered in industry. Tests were performed with several burner configurations and at a range of firing rates to determine the effects of various parameters on performance and emissions.

A host site was selected for field evaluation of the industrial prototype FIR burner. This site has three watertube boilers, each rated at $120,000 \mathrm{lb} / \mathrm{h}$ steam, firing coke-oven gas with natural gas as backup fuel. Environmental regulators have contacted the site regarding upcoming regulations on NOx emissions and haze (SOx emissions). The FIR burner could enable the site to comply with NOx emissions limitations. This host site was a good match for the FIR burner development. Baseline testing determined the current emissions and boiler baseline performance at several firing rates. In addition, the fuel-bound nitrogen (e.g. ammonia and hydrogen cyanide) content of the fuel was determined through analytical testing. A detailed design for the 174 million Btu/h industrial prototype burner was generated for application to the watertube boiler.

A 174 million Btu/h industrial prototype burner was constructed by Hamworthy Peabody, and installed at the coke-oven gas boiler site. A comprehensive burner evaluation was conducted firing both natural gas and actual coke-oven gas as generated during on-site production. 


\section{PHASE I - 20 MILLION BTU/H PROTOTYPE BURNER LABORATORY EVALUATION}

This section describes the 20 million Btu/h watertube boiler test facility and laboratory equipment used to evaluate the prototype FIR burner. Other discussion topics include the fuel supply, combustion air supply systems, and analytical instrumentation.

\section{0 million Btu/h Watertube Boiler Test Facility}

The FIR burner was evaluated on a 20 million Btu/h Cleaver Brooks watertube boiler, Model No. D-34. The boiler has a total heating surface of 1819 square feet and an American Boiler Manufacture Association furnace volume of 425 cubic feet, with a rated steam pressure of 270 PSIG. The present installation allows for operation at a steam pressure of 150 PSIG. The watertube boiler test facility is shown in Figure 2. It should be noted that the opening in the front boiler wall is larger than normal. In this research boiler, the larger opening allows for the evaluation of multiple burner sizes. Installation of the watertube boiler was typical to that encountered in an industrial setting, except there is no return of condensate because there is no process. Boiler feed water is supplied through city water connections and then softened before entering the make-up water tank. Additional chemicals are added to the tank to protect the boiler water walls. Steam is supplied to the tank and preheats the make-up water to $200^{\circ} \mathrm{F}$ before it enters the boiler. The steam generated by the boiler is vented to the atmosphere through a silencer, which is located above the roof. The breech connecting the stack to the boiler has five gas sampling ports. These sampling ports are used to verify that the flue gas composition is consistent through the entire cross section of the breech. Once verified, a single point measurement is sufficient for exhaust gas sample monitoring. The boiler stack is of typical field construction with a butterfly damper to provide backpressure in the boiler if needed. 


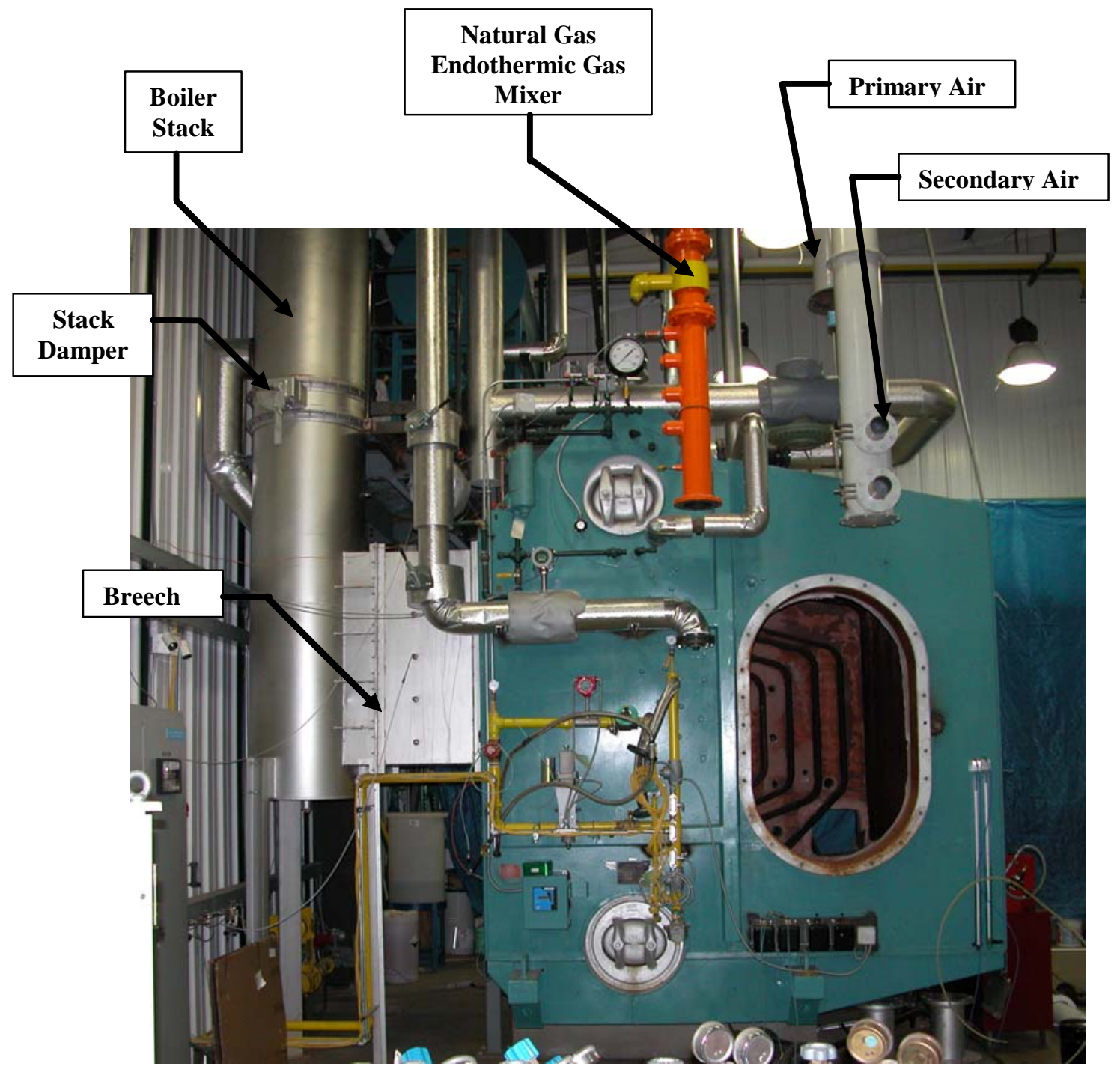

Figure 2. 20 MILLION BTU/H WATERTUBE BOILER TEST FACILITY AT GTI 


\section{The Fuel Supply}

The natural gas supply line to the burner is standard 2-inch pipe with a double block-and-bleed valve arrangement. The components from the supply end are a Roots flow meter, manual shutoff valve, gas pressure regulator, supply pressure gauge, Sierra mass flow meter, manual shutoff valve, supply pressure gauge, gas pressure regulator, low-pressure switch, safety solenoid valve, vent solenoid valve, second safety solenoid valve, and a high-pressure switch. The data from the Sierra mass flow meter is recorded directly to the data acquisition system. The gas supply line supplies gas to a North American flow control valve downstream of which the gas line branches into two separate, but parallel, lines equipped with limiting orifices and hand valves. The individual lines can supply metered natural gas to individual burners. Natural gas is combined with combustion air inside the burner.

Additional tests were to be conducted firing COG and COG doped with ammonia. Since COG was not readily available, the Project Team investigated alternatives. The use of tankers for individual gases proved uneconomical, so a mixture of natural gas and endothermic gas in proportions that closely matched the Wobbe index of the COG was used. Figure 3 shows the Surface Combustion model RX-4T endothermic gas generator rated at 12,000 CFH. The flow rate was measured with a Sierra mass flow meter and recorded directly to the data acquisition system. COG flow was regulated with a North American control valve and supplied to a mixer assembly where natural gas and endothermic gas were blended (see Figure 4). The endothermic gas generator was operated automatically through the safety control of the burner. This procedure ensured that the endothermic generator would shut down if there were a flame failure. Any excess endothermic gas was burned off and vented at the generator. Located downstream of the mixer assembly is a tap where ammonia was introduced in concentrations of zero to $1000 \mathrm{vppm}$. The ammonia component of the fuel was supplied by portable tanks that were regulated at the tank, and the ammonia was fed to the tap. The ammonia flow rate was measured with a rotameter and an MKS mass flow meter calibrated for ammonia. The MKS mass flow meter recorded the data directly to the data acquisition system. 


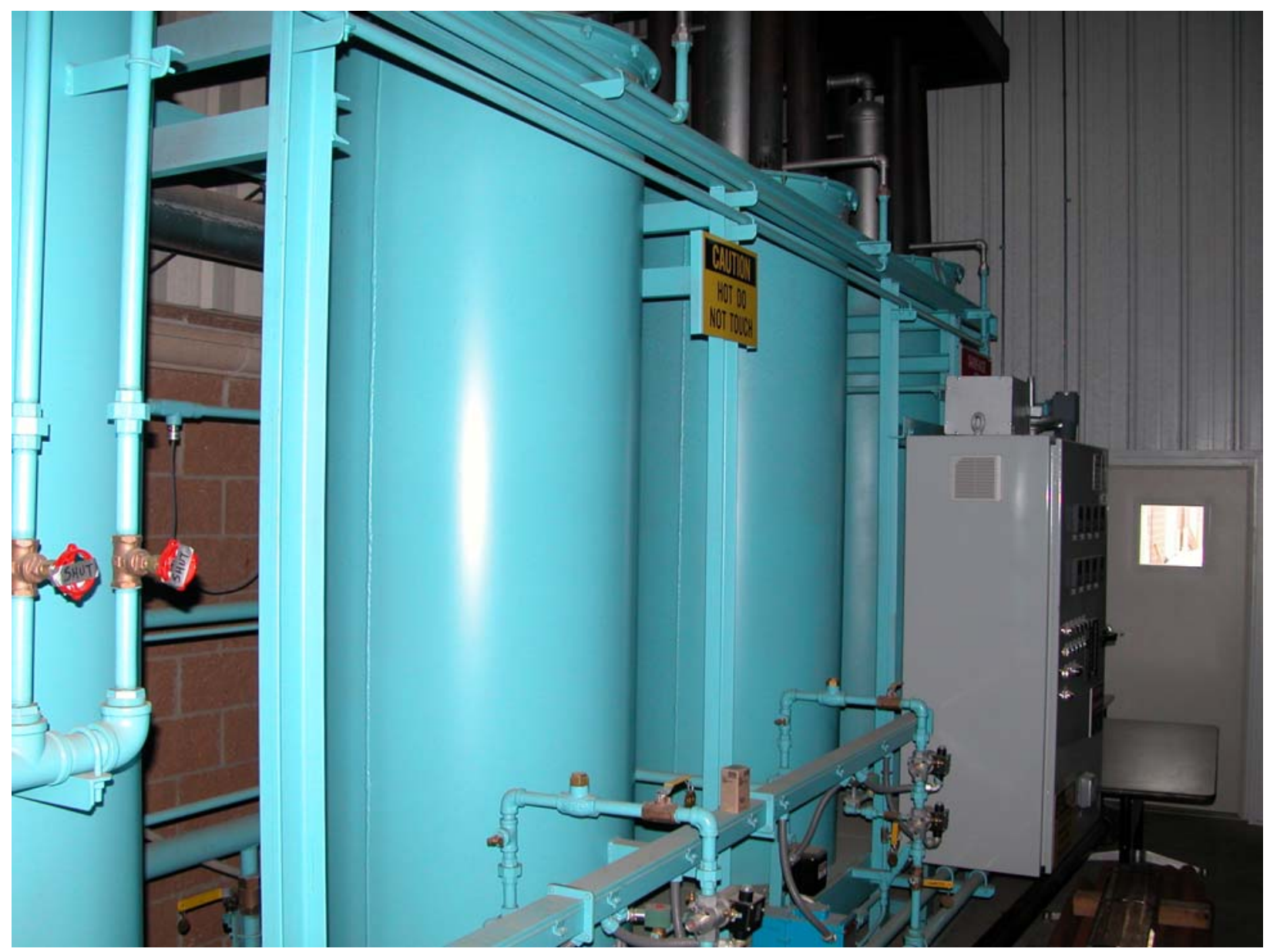

Figure 3. ENDOTHERMIC GAS GENERATOR 


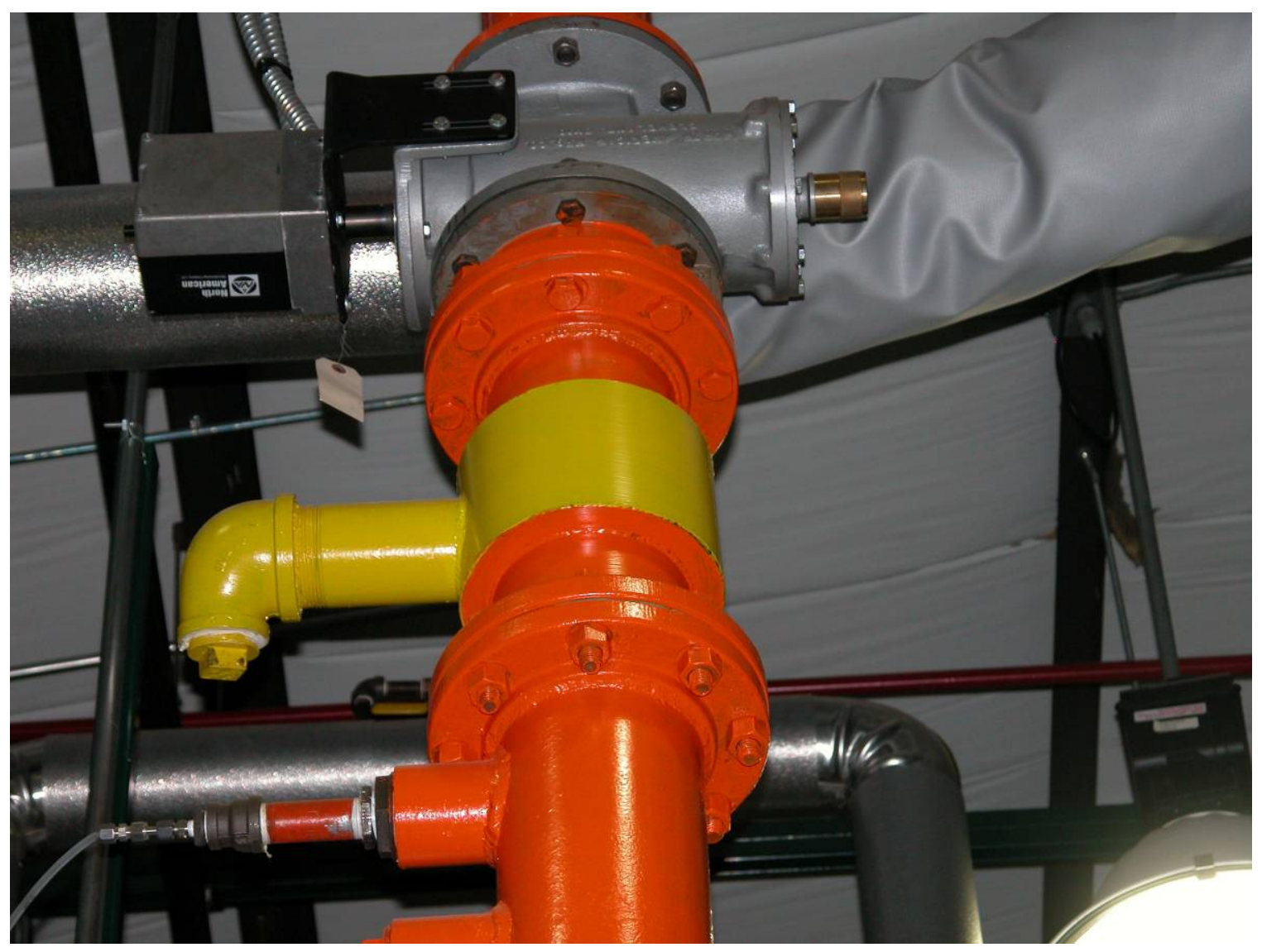

Figure 4. NATURAL GAS AND ENDOTHERMIC GAS MIXER ARRANGEMENT 


\section{Combustion Air Supply}

The combustion air is supplied by a New York Blower Company pressure blower, which is mounted near the burner, and piped to the burner. Combustion air flow is controlled via a cabinet-mounted variable frequency drive in conjunction with actuated butterfly valves on both the primary and secondary air lines. Flow rate for both the primary and secondary air is measured with Sierra mass flow meters, with the data recorded directly by the data acquisition system.

\section{Analytical Equipment and Measurements}

The data acquisition system collected data continuously at specified points during burner evaluation. The major flow rate measurements recorded were primary and secondary combustion air, natural gas, endothermic gas, and ammonia. Appropriate boiler operation parameters; and $\mathrm{NO} / \mathrm{NOx}, \mathrm{CO}, \mathrm{CO}_{2}, \mathrm{THC}$, and $\mathrm{O}_{2}$ emissions from the burner and in the exhaust gas, as well as exhaust gas temperature were recorded.

The static pressure at the combustion chamber exit, burner windbox, and fuel manifold were measured with manometers. Type "R" thermocouples were installed at the boiler exit and the endothermic gas supply piping. At various times during the tests, type " $\mathrm{K}$ " thermocouples were used to measure the recirculation insert and the secondary air tube temperatures.

The exhaust gas sample was drawn through a 1/4-inch-OD by 3-foot-long, stainless steel probe. The gas sample was withdrawn using oil-less vacuum pumps and passed through sample conditioning trains, which consist of the following:

- A water trap to remove any condensate.

- A membrane dryer for removing the moisture.

The sample conditioning trains are located near the probe and are followed downstream by Teflon sample lines to deliver the gas sample to the gas analyzers through a sample flow control and distribution panel. The control panel (shown in Figure 5) facilitates easy switching between gas sampling and instrument calibration. 


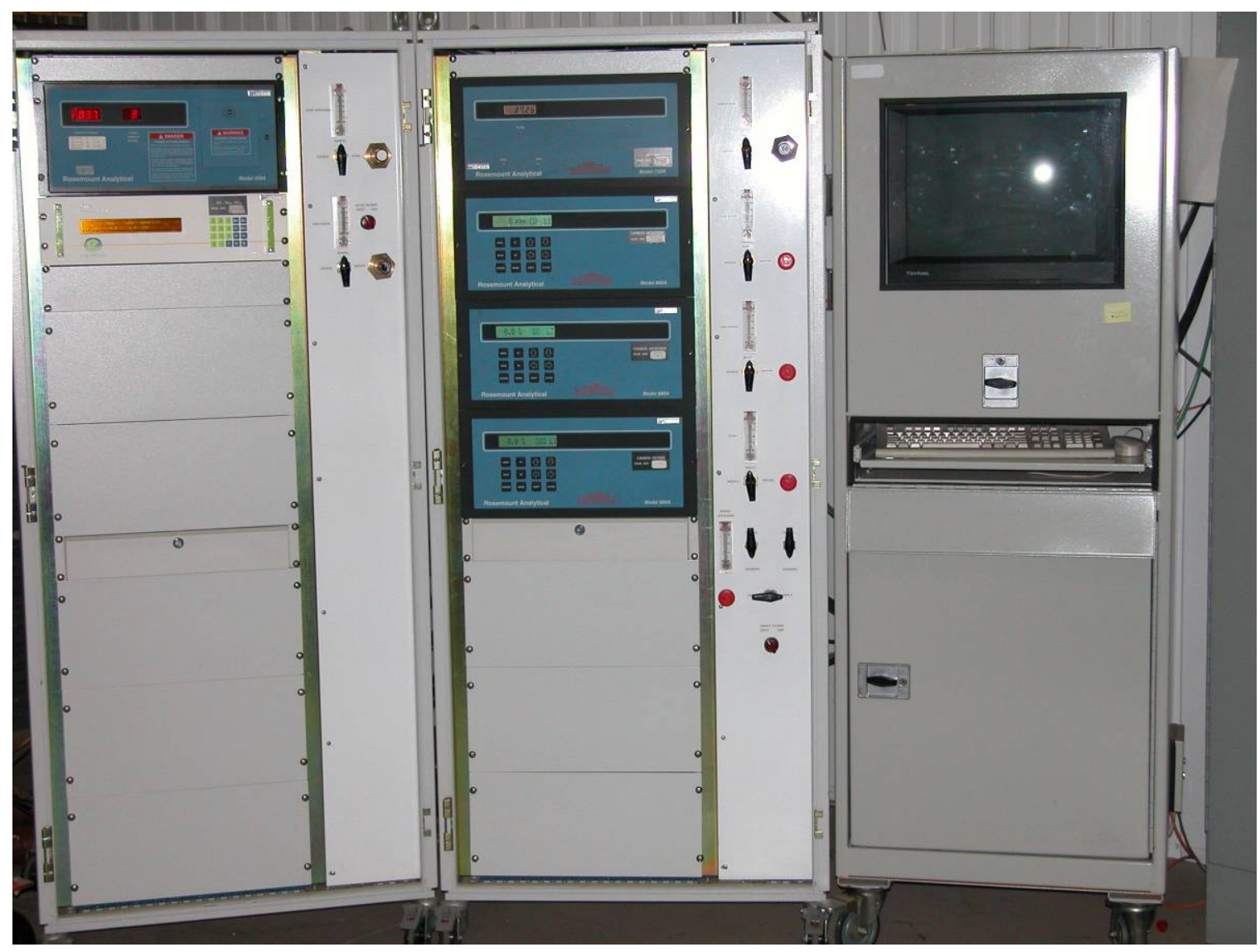

Figure 5. GAS SAMPLING FLOW CONTROL AND INSTRUMENTATION 
The flue gas composition was measured using continuous emission gas monitors. The following gas analyzers were utilized:

- An Eco Physics Model CLD 700 EL chemiluminescence NOx analyzer.

- A Rosemount Analytical Model 880A dispersed infrared carbon monoxide analyzer.

- A Rosemount Analytical Model 880A dispersed infrared carbon dioxide analyzer.

- A Rosemount Model 400 flame ionization total hydrocarbons analyzer.

- A Rosemount Analytical Model 755R paramagnetic oxygen analyzer.

All of the instruments were calibrated using pure nitrogen to establish the "zero" and an appropriate span gas to set the "gain." An analysis of the certified span gas mixture used during the evaluation follows:

$\begin{array}{ll}\text { NOx: } & 78.4 \text { vppm } \\ \text { CO (low): } & 924 \mathrm{vppm} \\ \text { CO (high): } & 24.93 \% \\ \mathrm{CO}_{2}: & 17.86 \% \\ \text { THC: } & 360.4 \mathrm{vppm} \\ \mathrm{O}_{2}: & 3.98 \%\end{array}$

The carbon monoxide content of the endothermic gas was also measured to verify that the fuel had the appropriate concentration of constituents required for simulation. Typical carbon monoxide concentrations were approximately $20.2 \%$. 


\section{Laboratory Testing}

The prototype FIR burner was evaluated on a 20 million Btu/h Cleaver Brooks watertube boiler, Model No. D-34. The boiler was equipped to fire either one or two burners, each rated at 10 million Btu/h. The reason for the multi-burner arrangement was that many boilers in the steel industry are field-erected and have multiple burners firing in the same combustion chamber. Prior FIR burner developments were strictly a single burner arrangement, and laboratory evaluation of a multi-burner arrangement would provide important information regarding burner interaction. The initial test plan started with a single burner arrangement and then, after some initial testing, finished with a multi-burner arrangement.

The prototype FIR burner was designed to fire two fuels: natural gas and COG. Since COG was not readily available, the Project Team investigated alternatives. Several different mixtures, are summarized in Table 5, were evaluated. The use of tankers for individual gases proved uneconomical, and a mixture of natural gas and endothermic gas that closely matched the Wobbe index of COG was chosen. The simulated COG mixture was $64.4 \%$ natural gas and $35.6 \%$ endothermic gas (Mixture 6). The simulated COG was doped with measured amounts of ammonia, in concentrations ranging from zero to $1000 \mathrm{vppm}$.

The prototype FIR burner proved to be a feasible approach to NOx reduction. Laboratory testing confirmed model predictions and determined the effectiveness of various NOx reduction approaches. Initial testing was conducted with a single-burner arrangement, as shown in Figure 6. Baseline data was collected for comparisons between the single- and multi-burner arrangements. 
Table 5. COG Alternative Mixtures

\begin{tabular}{|l|c|c|c|c|c|c|c|c|}
\hline Coke Oven Gas & Volume & Heating Value & Density & sp.gr. & Wobbe Index & Flow Rate & Flame Speed & Flow Rate \\
\hline & $\%$ & $B t u / \mathrm{ft}^{3}$ & $\mathrm{lb} / \mathrm{ft}^{3}$ & & $\mathrm{Btu} / \mathrm{ft}^{3}$ & $\mathrm{ft}^{3} / \mathrm{h}$ & $\mathrm{cm} / \mathrm{sec} 15^{\circ} \mathrm{C}$ & $\mathrm{ft}^{3} / \mathrm{hr}$ \\
\cline { 2 - 9 } & $\mathbf{1 0 0 . 0}$ & $\mathbf{5 5 1 . 5}$ & $\mathbf{0 . 0 2 6}$ & $\mathbf{0 . 3 4 4}$ & $\mathbf{9 4 0}$ & $\mathbf{9 , 0 6 6}$ & 97.74 & 36,266 \\
\hline
\end{tabular}

\begin{tabular}{|c|c|c|c|c|c|c|c|c|}
\hline Mixture 1 & Volume & Heating Value & Density & sp.gr. & Wobbe Index & Flow Rate & Flame Speed & Flow Rate \\
\hline & $\%$ & $\mathrm{Btu} / \mathrm{ft}^{3}$ & $\mathrm{lb} / \mathrm{ft}^{3}$ & & $\mathrm{Btu} / \mathrm{ft}^{3}$ & $\mathrm{ft}^{3} / \mathrm{h}$ & $\mathrm{cm} / \mathrm{sec} 15^{\circ} \mathrm{C}$ & $\mathrm{ft}^{3} / \mathrm{hr}$ \\
\hline & & 780.6 & 0.052 & 0.689 & 940 & 6,406 & 33.84 & 25,623 \\
\hline Natural Gas & 76.4 & & & & & 4,891 & & 19,563 \\
\hline Air & 23.7 & & & & & 1,515 & & 6,060 \\
\hline
\end{tabular}

\begin{tabular}{|c|c|c|c|c|c|c|c|c|}
\hline Mixture 2 & Volume & Heating Value & Density & sp.gr. & Wobbe Index & Flow Rate & Flame Speed & Flow Rate \\
\hline & $\%$ & $\mathrm{Btu} / \mathrm{ft}^{3}$ & $\mathrm{lb} / \mathrm{ft}^{3}$ & & $\mathrm{Btu} / \mathrm{ft}^{3}$ & $\mathrm{ft}^{3} / \mathrm{h}$ & $\mathrm{cm} / \mathrm{sec} 15^{\circ} \mathrm{C}$ & $\mathrm{ft}^{3} / \mathrm{hr}$ \\
\hline & & 324.8 & 0.009 & $\begin{array}{l}0.119 \\
\end{array}$ & 940 & 15,393 & 230.81 & 61,571 \\
\hline$\overline{\mathbf{H}_{2}}$ & 94.5 & & & & & 14,540 & & 58,160 \\
\hline \begin{tabular}{|l|}
$\mathrm{CO}$ \\
\end{tabular} & 5.5 & & & & & 853 & & 3,411 \\
\hline
\end{tabular}

\begin{tabular}{|c|c|c|c|c|c|c|c|c|}
\hline \begin{tabular}{|l|} 
Mixture 3 \\
\end{tabular} & Volume & Heating Value & Density & sp.gr. & Wobbe Index & Flow Rate & Flame Speed & Flow Rate \\
\hline & $\%$ & $\mathrm{Btu} / \mathrm{ft}^{3}$ & $\mathrm{lb} / \mathrm{ft}^{3}$ & & $\mathrm{Btu} / \mathrm{ft}^{3}$ & $\mathrm{ft}^{3} / \mathrm{h}$ & $\mathrm{cm} / \mathrm{sec} 15^{\circ} \mathrm{C}$ & $\mathrm{ft}^{3} / \mathrm{hr}$ \\
\hline & & 554.1 & 0.026 & 0.347 & 940 & 9,024 & 101.5 & 36,097 \\
\hline Natural Gas & 32.90 & & & & & 2,969 & & 11,876 \\
\hline$\widehat{\mathbf{H}_{2}}$ & 55.40 & & & & & 4,999 & & 19,998 \\
\hline $\mathrm{CO}$ & 11.70 & & & & & 1,056 & & 4,223 \\
\hline
\end{tabular}

\begin{tabular}{|c|c|c|c|c|c|c|c|c|}
\hline \begin{tabular}{|l|} 
Mixture 4 \\
\end{tabular} & Volume & Heating Value & Density & sp.gr. & Wobbe Index & Flow Rate & Flame Speed & Flow Rate \\
\hline & $\%$ & $\mathrm{Btu} / \mathrm{ft}^{3}$ & $\mathrm{lb} / \mathrm{ft}^{3}$ & & $\mathrm{Btu} / \mathrm{ft}^{3}$ & $\mathrm{ft}^{3} / \mathrm{h}$ & $\mathrm{cm} / \mathrm{sec} 15^{\circ} \mathrm{C}$ & $\mathrm{ft}^{3} / \mathrm{hr}$ \\
\hline & & 640.5 & 0.035 & 0.464 & 940 & 7,806 & 71.74 & 31,223 \\
\hline $\mathrm{CH}_{4}$ & 45.95 & & & & & 3,587 & & 14,347 \\
\hline $\mathrm{H}_{2}$ & 35.00 & & & & & 2,732 & & 10,928 \\
\hline $\mathrm{CO}$ & 19.05 & & & & & 1,487 & & 5,948 \\
\hline
\end{tabular}

\begin{tabular}{|c|c|c|c|c|c|c|c|c|}
\hline Mixture 5 & Volume & Heating Value & Density & sp.gr. & Wobbe Index & Flow Rate & Flame Speed & Flow Rate \\
\hline & $\%$ & $\mathrm{Btu} / \mathrm{ft}^{3}$ & $\mathrm{lb} / \mathrm{ft}^{3}$ & & $\mathrm{Btu} / \mathrm{ft}^{3}$ & $\mathrm{ft}^{3} / \mathrm{h}$ & $\mathrm{cm} / \mathrm{sec} 15^{\circ} \mathrm{C}$ & $\mathrm{ft}^{3} / \mathrm{hr}$ \\
\hline & & 642.1 & 0.035 & 0.467 & 940 & 7,786 & 68.69 & 31,145 \\
\hline $\mathrm{CH}_{4}$ & 50.85 & & & & & 3,959 & & 15,837 \\
\hline $\mathrm{H}_{2}$ & 32.76 & & & & & 2,551 & & 10,203 \\
\hline $\mathrm{CO}$ & 6.39 & & & & & 498 & & 1,990 \\
\hline AIR & 10.00 & & & & & 779 & & 3,115 \\
\hline
\end{tabular}

\begin{tabular}{|c|c|c|c|c|c|c|c|c|}
\hline \begin{tabular}{|l|} 
Mixture 6 \\
\end{tabular} & Volume & Heating Value & Density & sp.gr. & Wobbe Index & Flow Rate & Flame Speed & Flow Rate \\
\hline & $\%$ & $\mathrm{Btu} / \mathrm{ft}^{3}$ & $\mathrm{lb} / \mathrm{ft}^{3}$ & & $\mathrm{Btu} / \mathrm{ft}^{3}$ & $\mathrm{ft}^{3} / \mathrm{h}$ & $\mathrm{cm} / \mathrm{sec} 15^{\circ} \mathrm{C}$ & $\mathrm{ft}^{3} / \mathrm{hr}$ \\
\hline & & 727.6 & 0.046 & 0.599 & 940 & 6,872 & 42.48 & 27,488 \\
\hline \begin{tabular}{|l|} 
Natural Gas \\
\end{tabular} & 64.40 & & & & & 4,426 & & 17,702 \\
\hline Endothermic Gas & 35.60 & & & & & 2,446 & & 9,786 \\
\hline
\end{tabular}




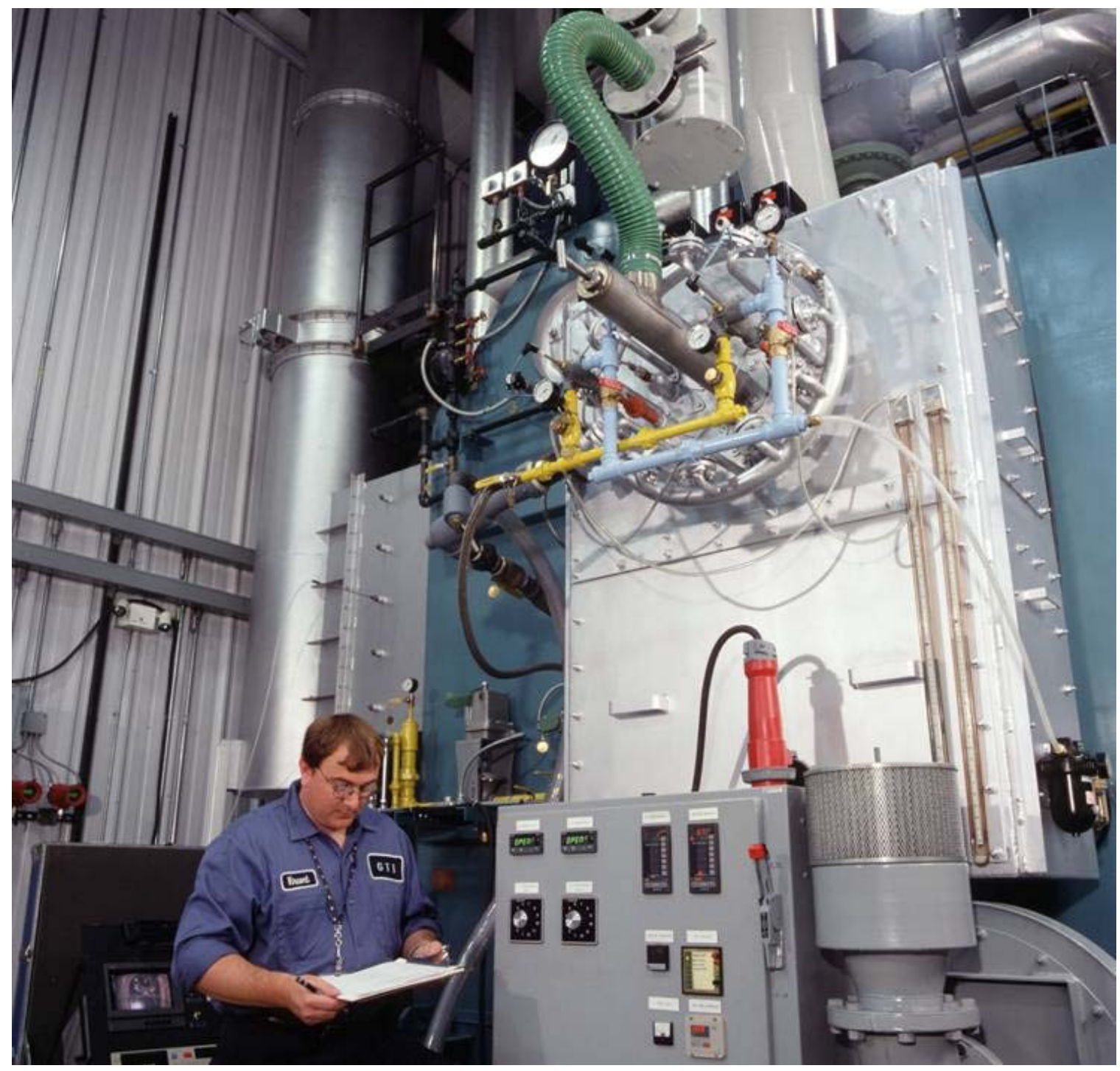

Figure 6. SINGLE BURNER PROTOTYPE ARRANGEMENT 
Initially, simulated COG was achieved with a mixture of natural gas and air (Mixture 1 in Table 5). The air supply was introduced via a commercially available mixer located in the natural gas supply line upstream of the entrance to the gas manifold at the burner interface. Even though the Wobbe index of this mixture matched that of COG, preliminary testing revealed this mixture to be sensitive and hard to maintain ignition at lower firing rates. Therefore, the majority of parametric testing was conducted firing natural gas.

Operation of a multi-burner arrangement, as shown in Figure 7, was conducted firing natural gas, simulated COG, and simulated COG doped with ammonia. Tests were conducted to evaluate the effects of ammonia concentration on the level of NOx formation. The ammonia concentration was quantified on a volumetric basis of the fuel measured in vppm. The majority of tests were conducted with ammonia concentrations of $0,500,750$, and $1000 \mathrm{vppm}$. In addition, the primary stoichiometry was varied to evaluate its effects on the level of NOx emissions. The primary stoichiometric ratio (PSR) was varied from 0.72 to 0.92 . The optimal PSR had been determined during previous FIR burner developments utilizing the air-staging approach.

One of the differences between this design and previous FIR burner designs was the method for introducing primary gas and primary air prior to combustion. Previous developments used designs that required higher natural gas pressures than are typically available for boilers in the steel industry. Therefore, a novel gas injector design was needed to accommodate the lower gas pressure available. For the prototype FIR burner, an axial gas jet was used to inject gas into the primary air flow. This arrangement required very little gas pressure. However, there were concerns about the mixing effectiveness of this arrangement. Preliminary evaluation of the prototype FIR burner investigated this concern. 


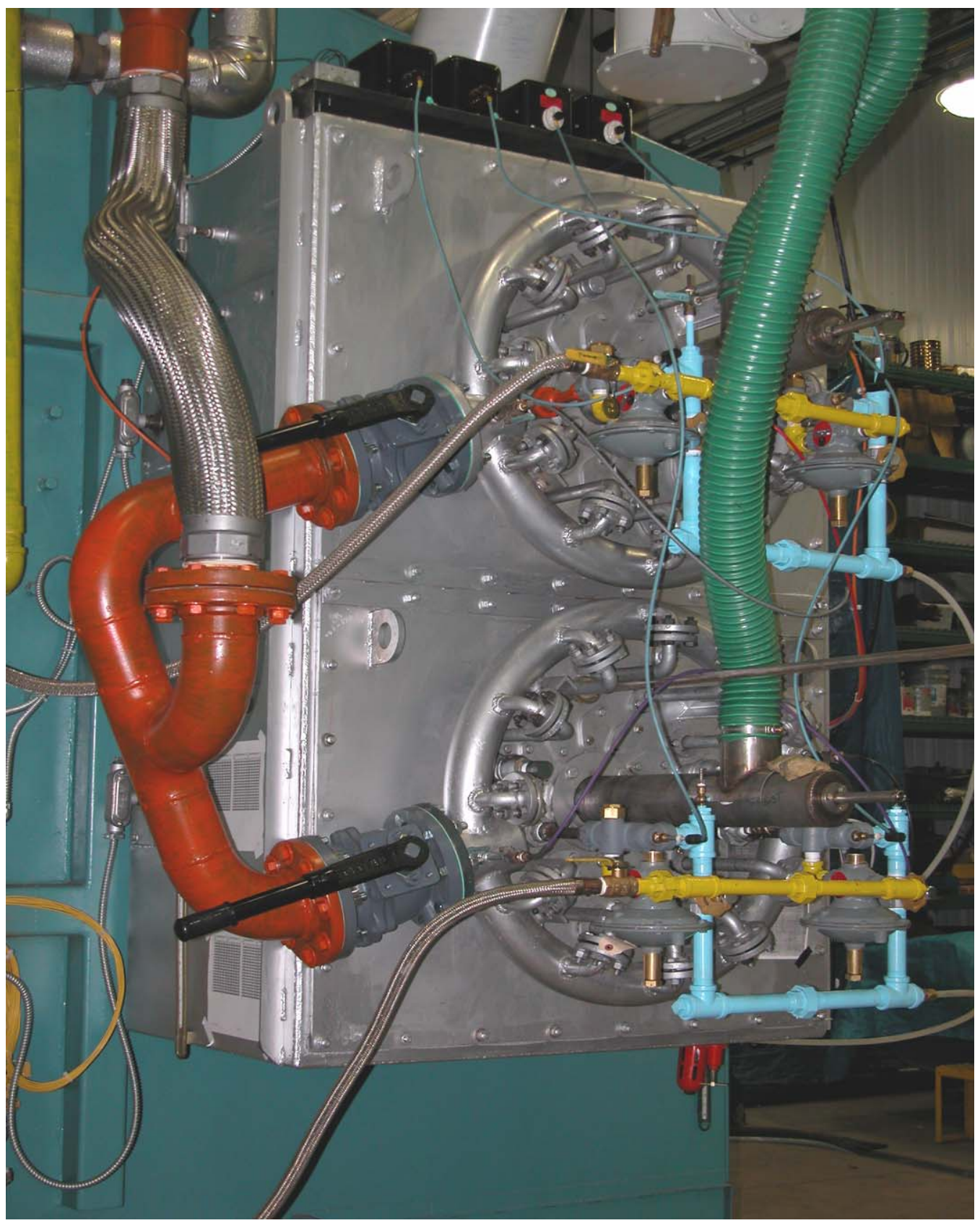

Figure 7. MULTI-BURNER PROTOTYPE ARRANGEMENT 
Tests with the axial gas injector design resulted in higher concentrations of $\mathrm{CO}$, especially at lower firing rates. The final design utilized the same type of axial jet, but a perforated plate covered the entrance of the nozzle throat and a washer was placed in the center. The washer served as a bluff body to force the gas flow around the washer and into the air flow. This arrangement reduced $\mathrm{CO}$ emissions by as much as $75 \%$.

Even with the improved mixing design, challenges still existed at lower firing rates. The Team attributed part of the problem to the inability of the secondary air to penetrate into the combustion products flowing from the primary zone. The initial secondary air tip design was made with a telescoping pipe where the inner pipe had six rows of holes. With this arrangement, the inner pipe could be adjusted by sliding it in and out of the outer pipe "on-thefly" from outside of the burner. This would either increase or decrease the number of rows depending on the direction of adjustment. Increasing the number of rows would decrease the velocity, and decreasing the number of rows would increase the velocity. Testing confirmed that the fewer rows enhanced penetration and CO burnout. Unfortunately, the CO levels were not reduced enough to meet the project goals.

A modification to the secondary air tip was designed and fabricated to increase the hole diameters. The increased diameter of the radial jet would provide more mass for momentum to penetrate further into the primary zone. This was done to rows one and three relative to the tip end. The second row of holes was sealed off to provide room for a clear and well-defined secondary jet profile. Rows four through six were also sealed. The modification resulted in a moderate improvement.

A second modification to the secondary air tip was designed and fabricated to physically bring the air injection point closer to the primary flame (as shown Figure 8). This resulted in a modified secondary air tip that was slightly angled so the secondary jets were aimed downstream of the combustion chamber rather than perpendicular to the flow. A similar type of design was used on previous FIR burners. Test results confirmed the ability to achieve firing rates below 5 million Btu/h. A steady flame was observed with low $\mathrm{CO}$ and $\mathrm{THC}$ emissions. This modified secondary air tip also produced a well-defined secondary flame structure. 


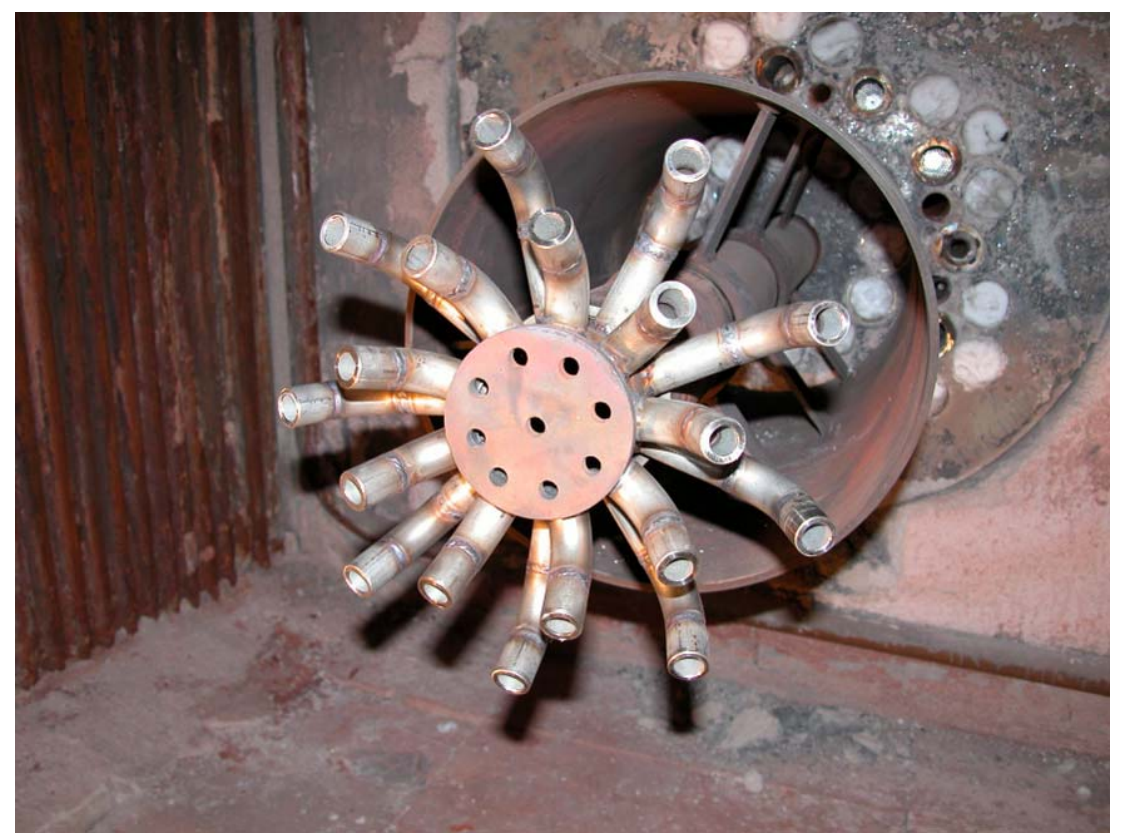

Figure 8. MODIFIED SECONDARY AIR TIP

Another parameter evaluated was the location of the primary flames. Tests were conducted firing the primary nozzles inside the recirculation insert rather than outside. Part of the interest of this arrangement was that the recirculation insert would help shield the primary nozzles from the colder flue gases that circulate along the furnace walls and quench the primary flame. In addition, firing inside the recirculation insert would result in higher recirculation insert temperatures that would enhance ammonia destruction.

Figure 9 compares two different burner configurations, each operating at 10 million Btu/h. Combustion was dramatically more stable with the primary nozzles firing inside the recirculation insert. However, NOx formation also increased dramatically.

The Project Team also evaluated the inner nozzle arrangement at several distances between the leading edge of the recirculation insert and the face of the refractory $(0,1,2$, and 4 inches). In all cases, with the exception of the smallest distance, there was minimal change in 


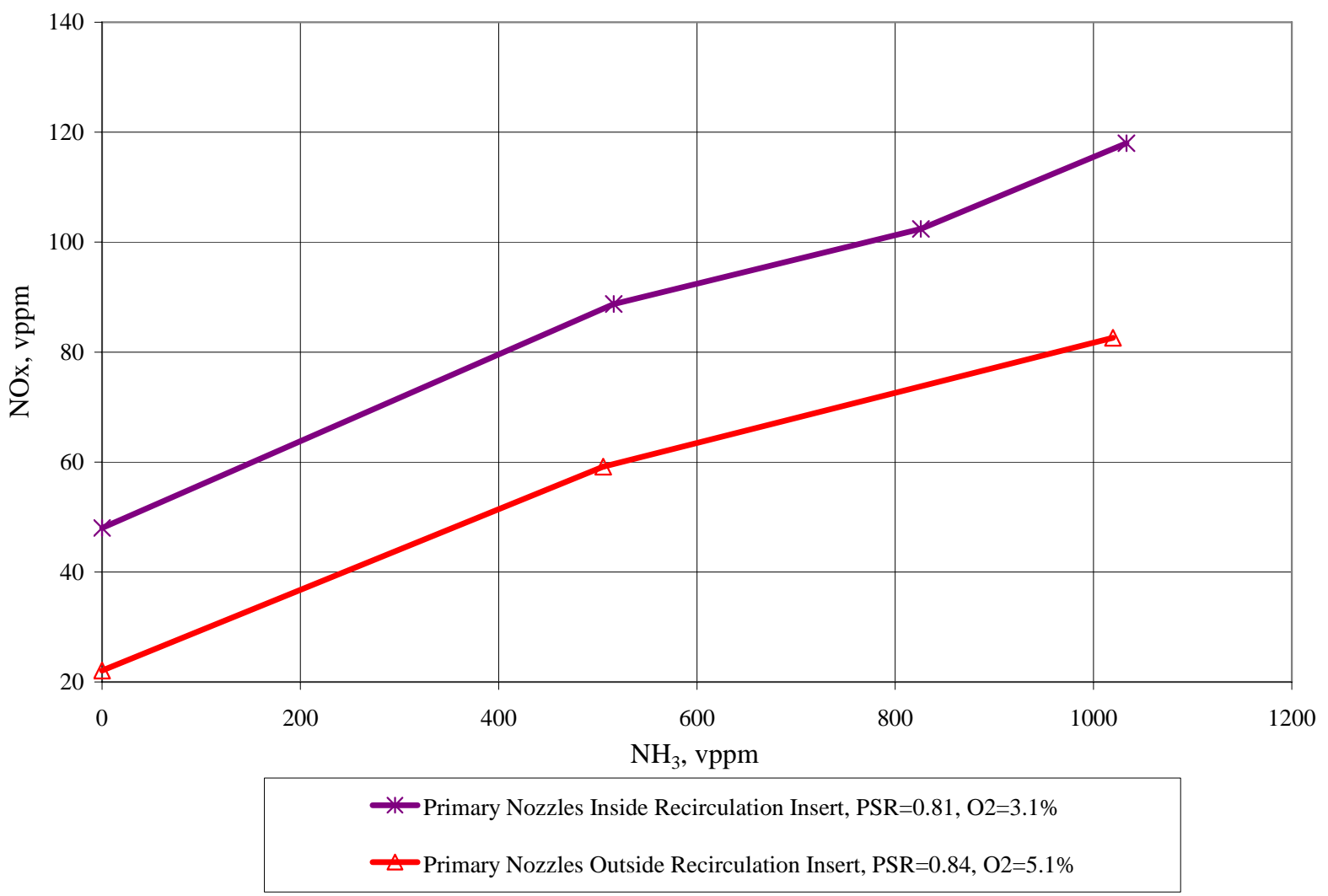

Figure 9. THE EFFECT OF PRIMARY NOZZLE FIRING LOCATION 
emission performance. The smallest distance provided the most stable combustion. An interesting phenomenon was observed with the smallest distance - a decrease in NOx levels by as much as $15 \%$ when the fuel was doped with ammonia. To further investigate the emissions, a water-cooled probe was used to measure emissions and temperature through the centerline of the flame for each burner. Measurements were acquired at the nozzle discharge; leading edge, center, and end of the recirculation insert; at the secondary air tip; and two feet downstream of the secondary air tip. The data revealed only minor differences between the two configurations.

The best overall burner performance is shown in Figure 10. Representative ammonia concentrations as documented in the steel industry ranged from 200 to $500 \mathrm{vppm}$. Ammonia concentrations were varied in the laboratory evaluation from zero to $1000 \mathrm{vppm}$ clearly extending the range encountered in industry. In industry, a present state-of-the-art burner operating with $500 \mathrm{vppm}$ ammonia in the fuel will produce about $280 \mathrm{vppm}$ NOx. The laboratory data reveals a direct relationship between NOx formation and ammonia concentration in the fuel. In addition, NOx formation increases as the PSR increases. When the laboratory burner operates with $500 \mathrm{vppm}$ ammonia in the fuel, NOx emissions ranged from 50 to $75 \mathrm{vppm}$. This, conservatively, is $75 \%$ less than state-of-the-art burner performance. When the same burner operates with $200 \mathrm{vppm}$ ammonia in the fuel, the corresponding NOx emissions ranged from 30 to $45 \mathrm{vppm}-84 \%$ less than state-of-the-art burner technology. Operation with $1000 \mathrm{vppm}$ ammonia in the fuel resulted in NOx levels between 75 and $105 \mathrm{vppm}$.

Another method of showing the NOx formation as a function of the fuel and PSR would be to examine the fuel-bound component of NOx formed. The fuel-bound NOx, or the NOx formed from ammonia, is estimated by subtracting the measured NOx with no ammonia in the fuel from the measured NOx with ammonia in the fuel. Figure 11 shows this comparison and the threshold that exists (represented as a dashed line). The threshold represents the case where all ammonia in the fuel passes through to the stack un-reacted. Data plotted below this threshold signifies a reduction or destruction of fuel-bound NOx. Comparing the concentration of ammonia in the fuel and air with the concentration of the fuel formed NOx in the products of combustion is an indication of the effectiveness of a combustion process. 


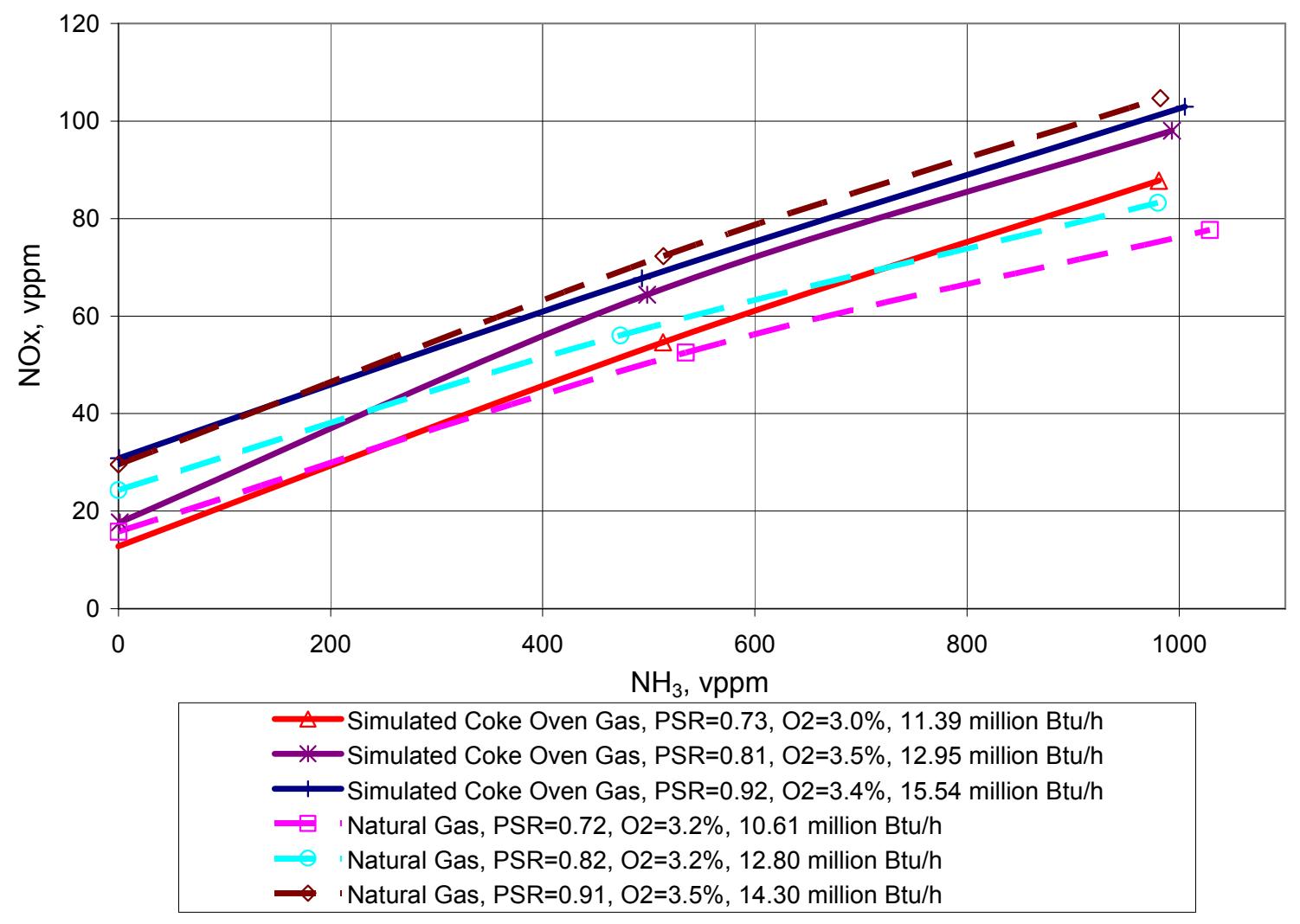

Figure 10. NOX FORMATION IS A FUNCTION OF AMMONIA CONCENTRATION 


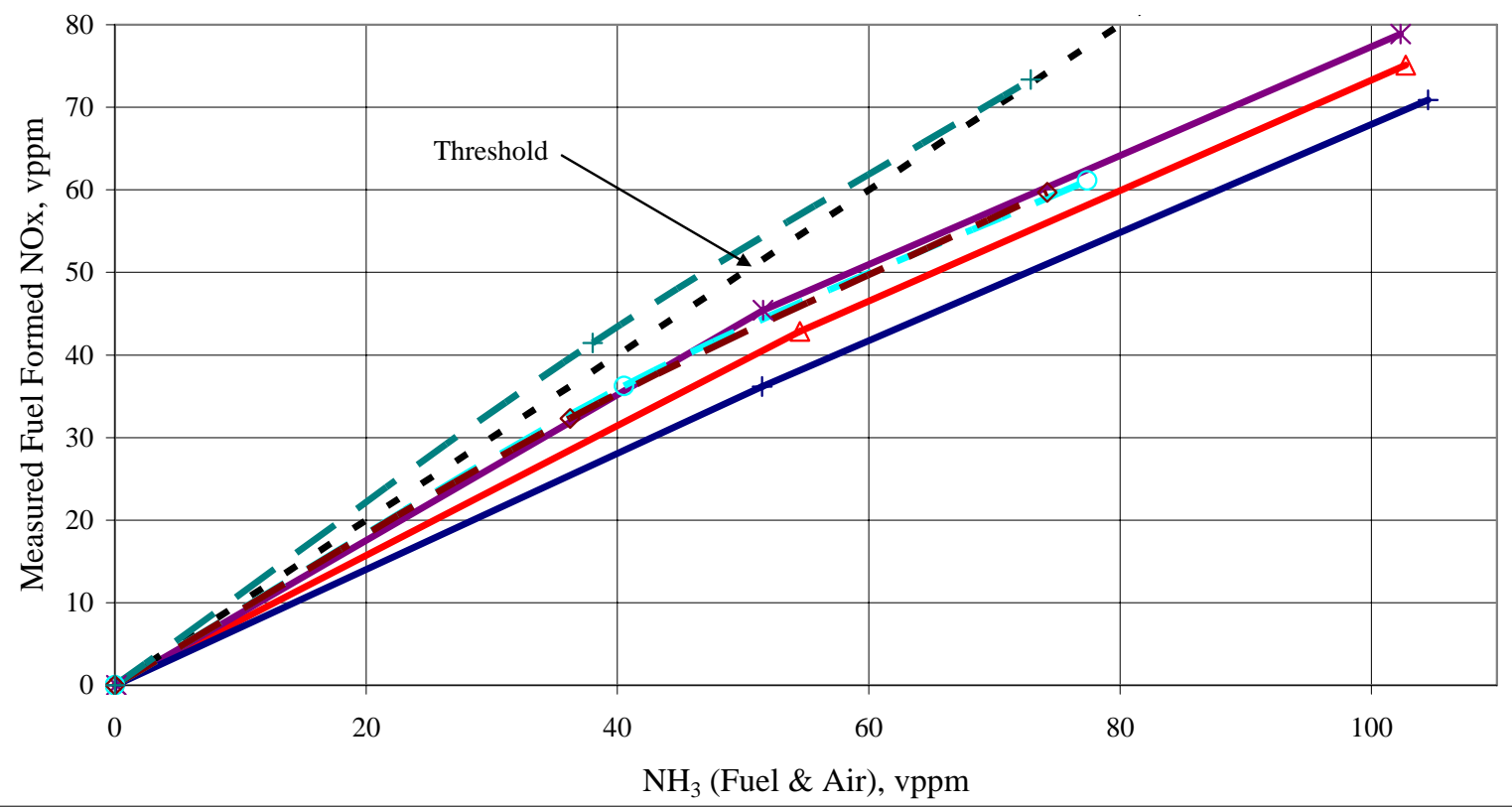

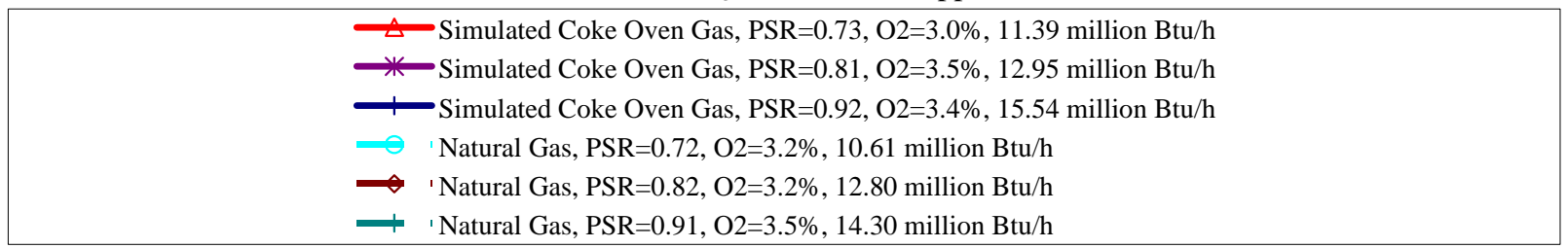

Figure 11. FUEL-FORMED NOx AS A FUNCTION OF AMMONIA CONCENTRATION 


\section{PHASE II - FULL-SCALE FIELD EVALUATION AT COKE-OVEN GAS BOILER SITE}

This section describes the 174 million Btu/h industrial watertube boiler field test. An FIR burner was evaluated under actual operating conditions in a full-scale field test to establish the performance necessary for subsequent commercialization.

\section{Coke-Oven Gas Boiler Host Site}

A host site was selected for field evaluation of the industrial prototype FIR burner. The site has three watertube boilers each rated at $120,000 \mathrm{lb} / \mathrm{h}$ steam firing coke-oven gas with natural gas as backup fuel. Environmental regulators have contacted the site regarding upcoming regulations on NOx emissions and haze (SOx emissions). The FIR burner could enable the site to comply with NOx emissions regulations. The site was a good match for the FIR burner development for boilers in the steel industry. The burner/boiler system, as shown in Figure 12, was a custom designed system engineered and provided to the host site specifications by the McBurney Corporation. The burner/boiler system consists of a Nebraska watertube boiler, Hamworthy Peabody burner, forced draft fan, forced draft fan turbine, induced draft fan, control system, steam piping, coke-oven gas piping, natural gas piping, and propane piping complete with all associated valves, fittings, and instrumentation required for each sub-system.

The boiler is a Nebraska Boiler Company integral furnace D-type package watertube boiler. The boiler is capable of continuously generating $120,000 \mathrm{lb} / \mathrm{h}$ steam flow while firing COG or natural gas.

The burner is a Hamworthy Peabody scroll type burner with an integral gas ring capable of firing COG, natural gas, or propane. Included in the burner system is a natural gas class 1 pilot. Based on operator choice the pilot can be operated as an intermittent or interrupted style pilot capable of firing up to $10 \%$ of main burner fuel input.

The combustion air is supplied with a forced draft (FD) fan manufactured by Twin City Fan. The fan size is 450 HIB-24, with a backward curved wheel design, capable of supplying adequate air to fire COG or natural gas at a fan speed of $1780 \mathrm{rpm}$. The fan is direct coupled to the forced draft fan turbine which is the primary motive driver. The FD fan turbine is a Coppus RLA 23E, two row Curtis wheel turbine capable of delivering $200 \mathrm{HP}$ at $1780 \mathrm{rpm}$ at the conditions for steam pressure of $200 \mathrm{PSIG}$, steam temperature of $525^{\circ} \mathrm{F}$, and a steam back pressure of 15 PSIG. 


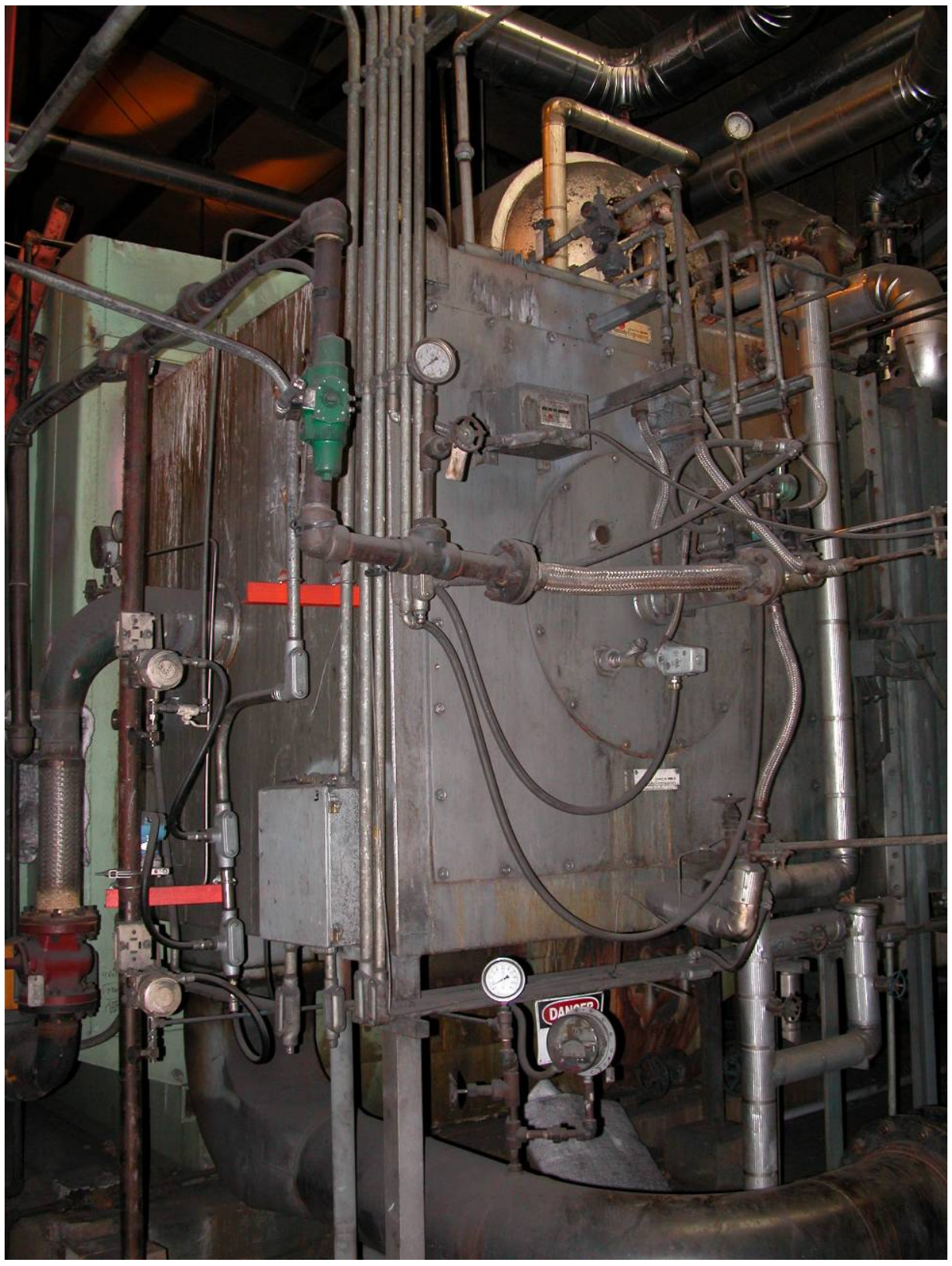

Figure 12. HAMWORTHY PEABODY BURNER AT COKE-OVEN GAS BOILER SITE 
The Burner Management System (BMS) consists of a boiler control panel, oxygen analyzer with oxygen trim, air flow sensor/transmitter, natural gas flow sensor/transmitter and various other transmitters and switches for controlling the burner/boiler. The major components of the control panel consist of Bailey Strategic Loop Controllers, Bailey Command Sequence Controllers, Bailey Computer Interface Controller, Honeywell Chart Recorder and various miscellaneous electronic components. From the control panel, the operator can select the desired fuel. The boiler control panel provides a local operator station to start-up and shut-down the burner/boiler system.

The oxygen analyzer is an AMETEK Series 2000 with a WDG-INSITU probe. The analyzer provides the signal for the oxygen trim controller. This signal allows for biasing of the combustion air signal to the fuel controller for the selected fuel. The oxygen probe is located in the flue gas duct at the rear of the boiler.

The air flow sensor used for combustion air flow measurement is a Kurz Model 455JRLIA. The analyzer provides the air flow signal for the FD fan damper controller. The air flow sensor is located in the FD fan inlet duct just prior to the FD fan inlet damper.

The Combustion Control System (CCS) is a fully metered and cross-limited system. It provides for the individual firing of three fuels (although not at the same time) and allows for on-line fuel switching. The CCS interacts with the BMS for boiler purge, burner light-off, and provides various analog signals to the BMS.

The COG flow rate was measured with a venturi flow meter manufactured by Fluidic Techniques. The flow meter was rated between zero and 400,000 SCFh and was 14-inch internal diameter. The natural gas flow was measured with a Rosemount vortex shedding flow meter; whereas, steam flow rate was measured with an orifice plate. 


\section{Baseline Testing}

Baseline testing of the Hamworthy Peabody burner was performed in October 2003. Testing was conducted firing COG. The propane infrastructure was not in place and natural gas firing capabilities were never fully deployed; therefore, baseline testing with these fuels was not possible.

The flows, pressures, and temperatures were all transmitted through the boiler control panel and displayed in the boiler control room. Pressure data for the steam drum, COG header, and furnace were measured with transducers supplied at the site and displayed in the boiler control room. The burner windbox pressure was measured with a manometer and the stack temperature with a type " $\mathrm{K}$ " thermocouple, both measurements were manually recorded during data collection.

The flue gas composition was measured using a Horiba model PG-250 portable continuous emission gas monitor. Emissions measurements included $\mathrm{NOx}, \mathrm{CO}, \mathrm{CO}_{2}$, and $\mathrm{O}_{2}$. The Horiba uses chemiluminescence (cross-flow modulation) for NOx; non-dispersive infrared detection for $\mathrm{CO}$ and $\mathrm{CO}_{2}$; and a zirconium oxide sensor for $\mathrm{O}_{2}$ measurements. For THC measurement, a Rosemount Model 400 flame ionization analyzer was used. Both instruments were calibrated prior to testing and after testing on each day. All calibration gases were certified standard grade for each of the species analyzed.

The exhaust gas sample was drawn through a 1/4-inch-OD by 3-foot-long, stainless steel probe. The gas sample was withdrawn using oil-less vacuum pumps and passed through sample conditioning trains, which consist of the following:

- A water trap to remove any condensate.

- A membrane dryer for removing the moisture.

The sample conditioning trains are located near the probe and are followed downstream by Teflon sample lines to deliver the gas sample to the gas analyzers through a sample flow control and distribution panel.

On October 2, 2003; an independent analytical laboratory, visited the coke-oven gas boiler site and collected samples of the COG to determine ammonia and hydrogen cyanide content. All samples collected for the ammonia analysis were collected in $0.1 \mathrm{~N}$ sulfuric acid; whereas, the 
hydrogen cyanide samples were collected on soda lime. The samples were acquired at two locations; before and after the scrubber (process line). These results are summarized in Table 6.

Table 6. COG Analysis during Baseline Testing

\begin{tabular}{|l|l|l|}
\hline Sample description & $\begin{array}{l}\text { Hydrogen Cyanide } \\
\text { Content, } \\
\text { vppm }\end{array}$ & $\begin{array}{l}\text { Ammonia Content, } \\
\text { vppm }\end{array}$ \\
\hline Process line & NM & 457 \\
Before scrubber & 86.6 & 4219 \\
Process line & 64.0 & 541 \\
\hline
\end{tabular}

Burner performance during baseline testing is represented graphically in Figure 13. Both NOx and $\mathrm{CO}$ emissions increase gradually as the firing rate increased over the range. At low fire; 46 million Btu/h, NOx emissions where $170 \mathrm{vppm}$ and increased at full load; 158 million Btu/h, to $241 \mathrm{vppm}$. CO emissions remained below $155 \mathrm{vppm}$ across the entire firing range. The oxygen content is relative steady due to the oxygen trim controller. 


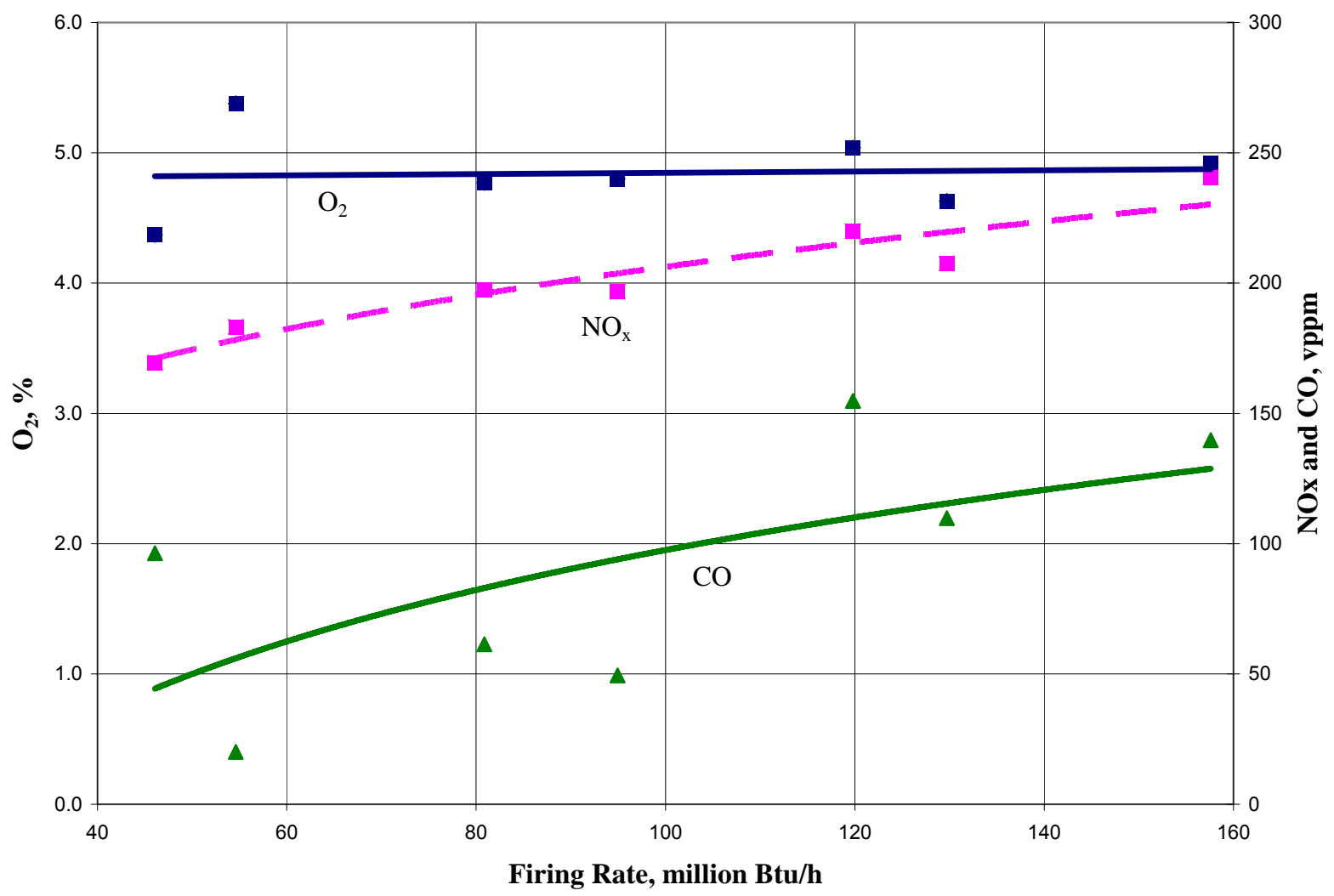

Figure 13. BASELINE EMISSIONS DATA FIRING COG 


\section{FIR Industrial Prototype Burner}

The 174 million Btu/h industrial prototype burner was fabricated, installed, and evaluated at the coke-oven gas boiler site. The burner design combines two-stage combustion with partially premixed, fuel-rich, first stage gases and forced internal recirculation of products of partial combustion to reduce formation of "thermal NOx" as well as "prompt NOx." The secondary air enters downstream of the primary combustion zone to complete the combustion process. Enhanced internal recirculation maximizes heat transfer to the process fluid surrounding the combustion space and lowers the peak flame temperature (in both the primary and secondary combustion zones). A multi-burner arrangement was chosen for the coke-oven gas boiler site as shown in Figure 14. The burners are supplied through a common windbox with primary combustion air and are not operated independently. The installation has one manifold for COG and one manifold for natural gas.

The distribution between primary and secondary combustion air flows was accomplished through a branch in the secondary air supply off of the main combustion air duct as shown in Figure 15. Downstream of the branch, in the main combustion air duct supplying the primary zone adjacent to the windbox, is an opposed blade damper. The damper was intended to be set at one point, as determined during burner shakedown, and to remain fixed during automatic operation of the burner. Each secondary air duct is complete with a mass flow meter to measure air flow and a flow control valve to adjust the distribution of primary/secondary combustion air across the firing range.

The FIR burner was equipped with dual natural gas pilots. The pilots operated in conjunction with each other and would operate intermittently as with the baseline burner. Each pilot was rated at $450,000 \mathrm{Btu} / \mathrm{h}$ input.

The design of the 174 million Btu/h industrial prototype burner allowed for firing either COG or natural gas. A dual manifold arrangement was use to facilitate this capability. The fuel spargers that provided gas to the individual nozzles were designed with concentric dual pipes where COG would be transported along the axis and natural gas would be transported along the periphery. The arrangement is shown in Figure 16. The center pipe was used for COG because it would be less susceptible to tar build up over time and would be easier to clean. The overall design allowed for the center pipe to be removed for cleaning purposes. 


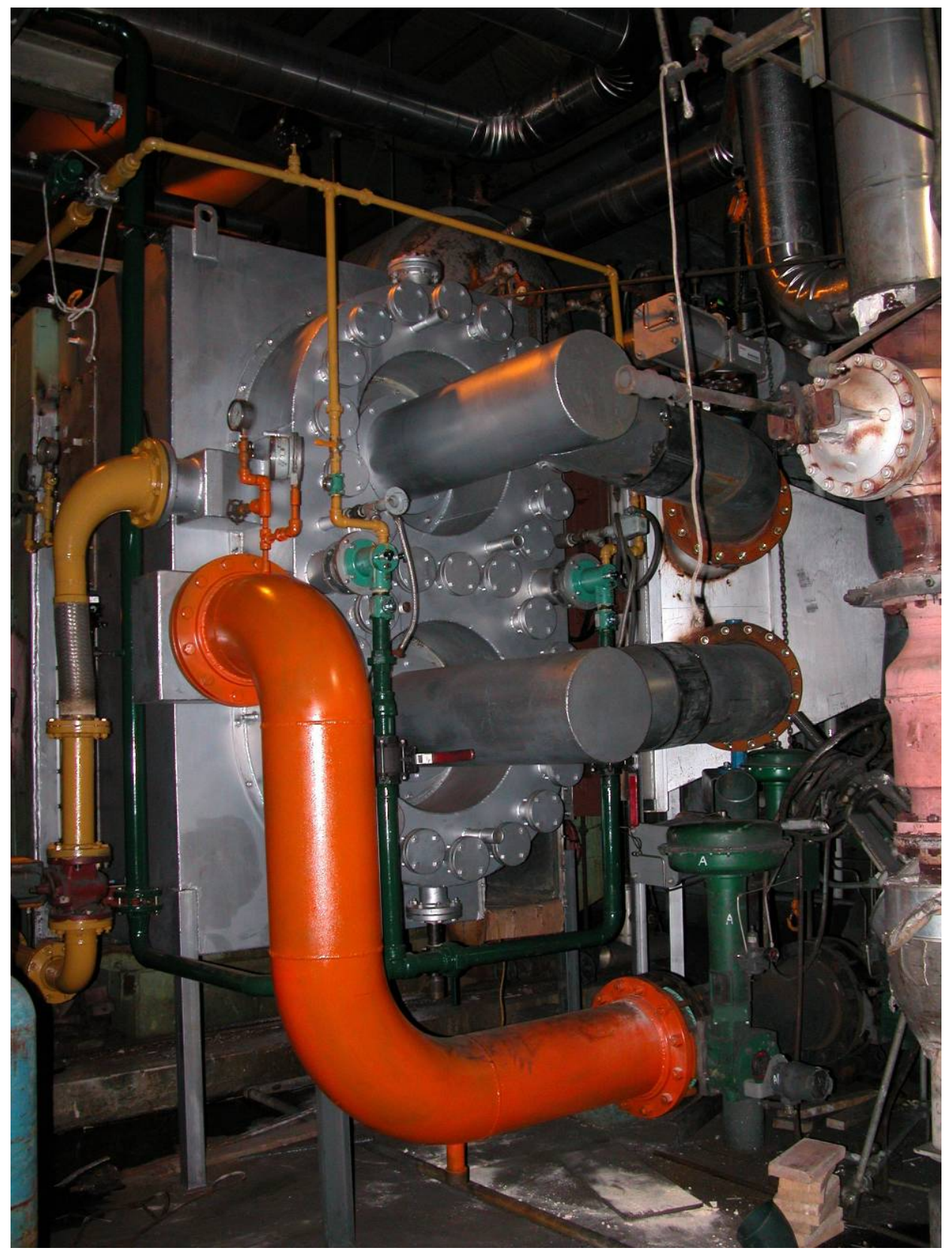

Figure 14. FIR BURNER INSTALLATION AT COKE-OVEN GAS BOILER SITE 


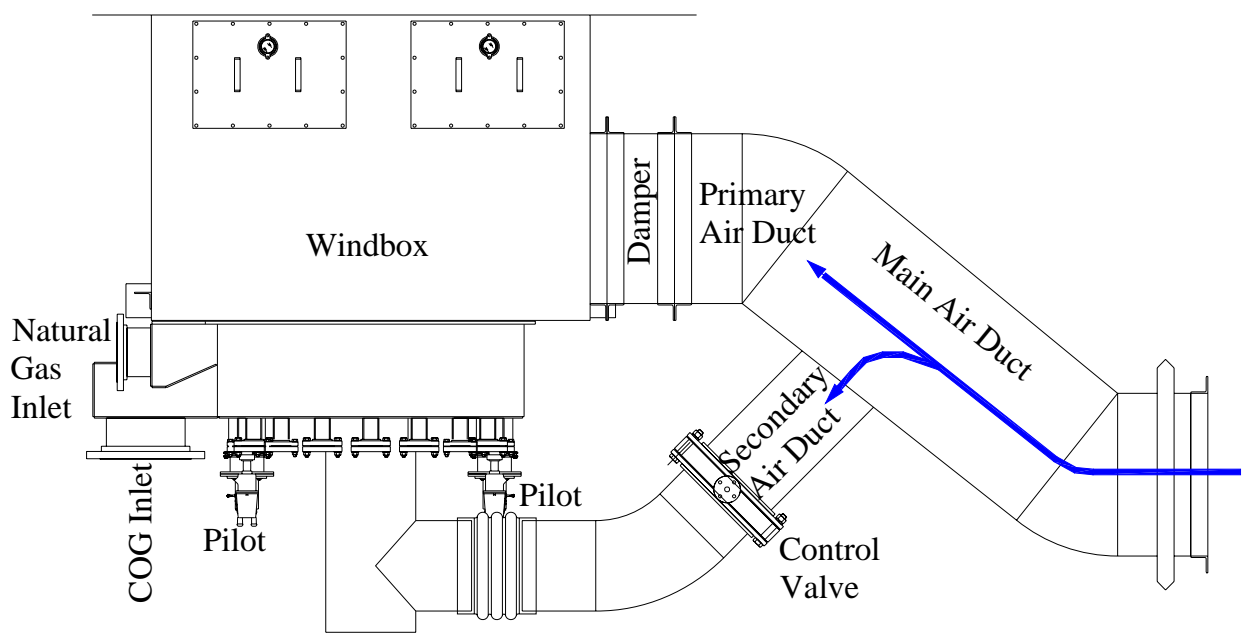

Figure 15. BURNER ARRANGEMENT TOP VIEW

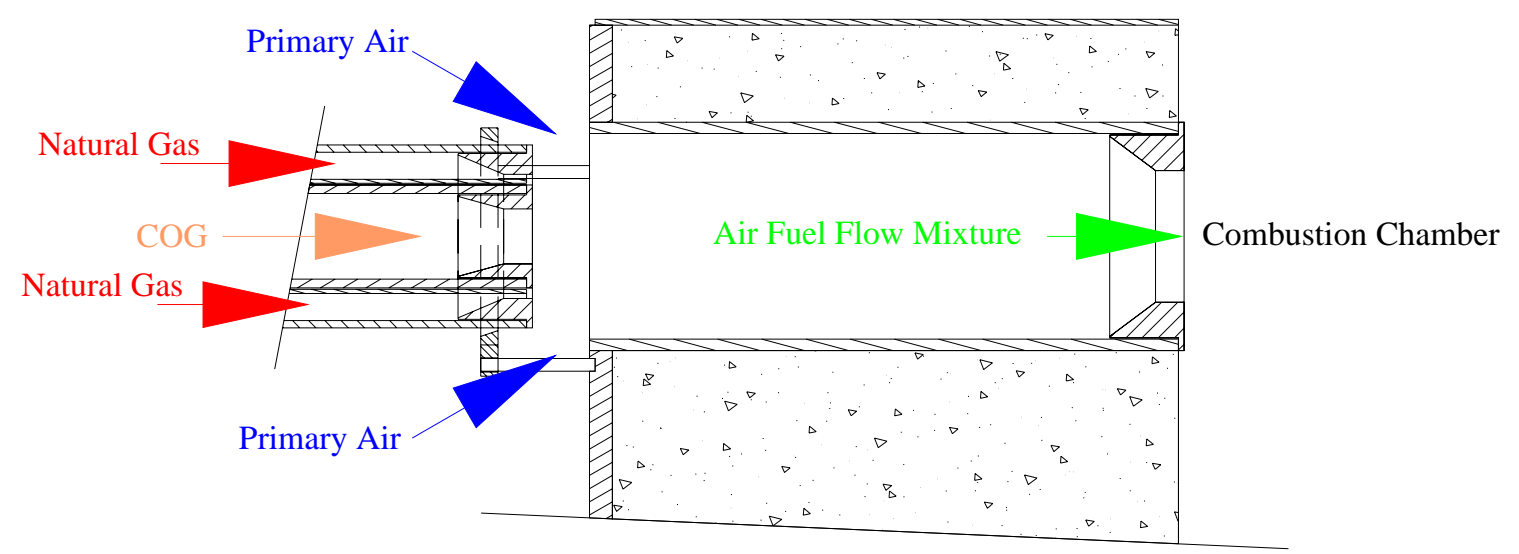

Figure 16. FUEL SPARGER/NOZZLE ARRANGEMENT 


\section{Burner Modeling}

Computational fluid dynamic (CFD) code was also used for assisting design calculations for the 174 million Btu/h industrial prototype burner at the coke-oven gas boiler site. The physical models utilized in the calculations are presented below in Table 7.

Table 7. Physical Models Used for CFD Calculations

\begin{tabular}{|l|l|}
\hline Model & Settings \\
\hline Firing rate, million Btu/h & 46 \\
Primary COG flow rate, SCFh & 88,839 \\
Secondary COG flow rate, SCFh & 0 \\
Primary air flow rate, SCFh & 299,833 \\
Secondary air flow rate, SCFh & 159,911 \\
Primary inlet velocity, $\mathrm{ft} / \mathrm{s}$ & 45.8 \\
Secondary inlet velocity, ft/s & 44.9 \\
Primary inlet temperature, ${ }^{\circ} \mathrm{F}$ & 80 \\
Secondary inlet temperature, ${ }^{\circ} \mathrm{F}$ & 220 \\
\hline Inlet species composition (mass fraction): & \\
\hline $\mathrm{CH}_{4}$ & 0.0496 \\
$\mathrm{O}_{2}$ & 0.211 \\
$\mathrm{H}_{2}$ & 0.0103 \\
$\mathrm{CO}^{-}$ & 0.0147 \\
$\mathrm{H}_{2} \mathrm{O}$ & 0.0118 \\
\hline
\end{tabular}

The influence of turbulence on the reaction rate was modeled using the eddy-dissipation model of Magnussen and Hjertager. The Arrhenius reaction rates were combined with the eddydissipation model reaction rates (adjusted to provide postulated interaction between chemical reaction and turbulent mixing). The parameters of the model were fit based on the test results of the 20 million Btu/h prototype burner. The following two-step chemistry model, representing the combustion of methane in air, was implemented:

Step 1: $\mathrm{CH}_{4}+3 / 2\left(\mathrm{O}_{2}+3.76 \mathrm{~N}_{2}\right) \rightarrow \mathrm{CO}+2 \mathrm{H}_{2} \mathrm{O}+3 / 2 * 3.76 \mathrm{~N}_{2}$

Step 2: $\mathrm{CO}+1 / 2\left(\mathrm{O}_{2}+3.76 \mathrm{~N}_{2}\right) \rightarrow \mathrm{CO}_{2}+1 / 2 * 3.76 \mathrm{~N}_{2}$ 
Radiative heat transfer within the burner was modeled using the P-1 radiation model in FLUENT $^{\circledR}$. Turbulent flow simulations were performed using the standard two equation $\mathrm{k}-\varepsilon$ model of Fluent with the standard wall functions. Default settings in FLUENT ${ }^{\circledR}$ were used for turbulence model settings.

The CFD mesh was built based on the current understanding of the modeled flame. A fine mesh was built for the area around the fuel inlet jets, the beginning and the end of the recirculation insert, and the secondary flame zone. Special attention was given to the recirculation insert surface area. The mesh was built in such way to keep y+ values around 30 near the surface. The adaptation of the mesh near the insert surface fuel inlets and secondary air inlet was carried out during the solution.

Physical properties of the gases involved (heat capacity and conductivity) were computed from mixture rules for species dependence. The heat capacity of the mixture was assumed to be a function of temperature using the polynomial fit. The density of the mixture was changed to an incompressible ideal gas, i.e., the density changes as a function of temperature and species concentrations, and the variability with pressure was ignored. The molecular viscosity was assumed to be a constant. The boundary conditions used in the analysis were derived from an engineering study of the coke-oven gas boiler.

Results of the modeling showed that: NOx is mostly produced in hot zones in the second stage of the flame (average $90 \%$ of the total NOx production). Flame analysis showed three possible ways to decrease local peak temperatures:

- Promote more uniform mixing of the first-stage gases by tailoring the arrangement of primary nozzles to the combustion chamber profile and aspect ratio. Figure 17 shows the presence of hot spots due to the refractory floor.

- Injecting secondary air in an array of single jets.

- Increasing the proportion of heat release from the primary zone, thus reducing the flame temperature of second-stage combustion. 
Bottom Wall is Refractory
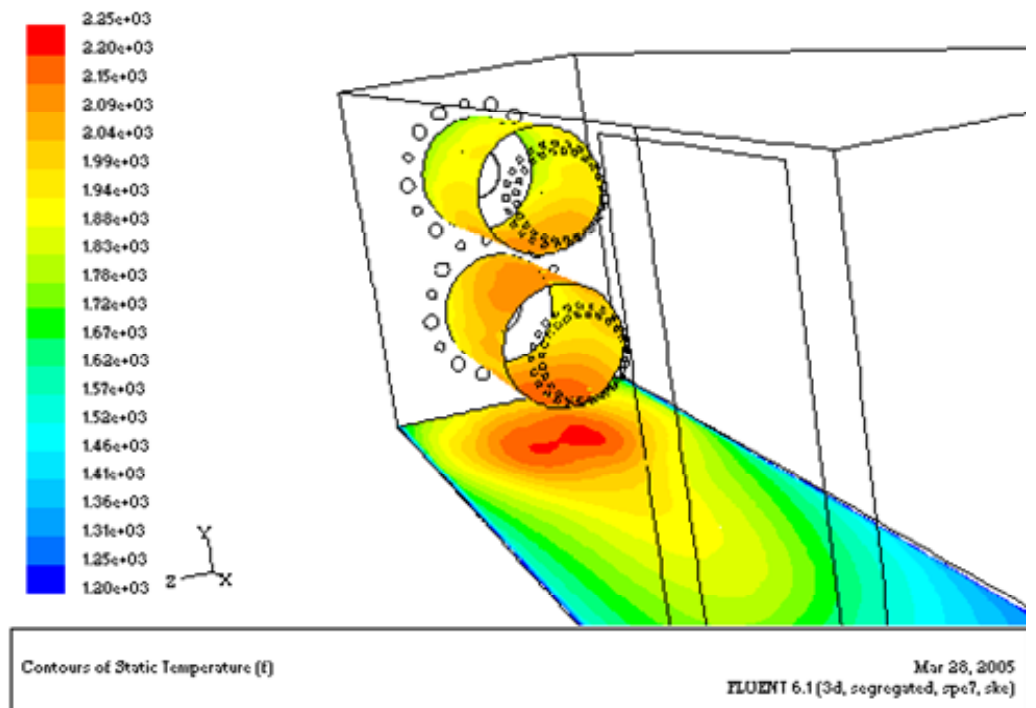

Bottom Wall is Watertube at $600^{\circ} \mathrm{F}$

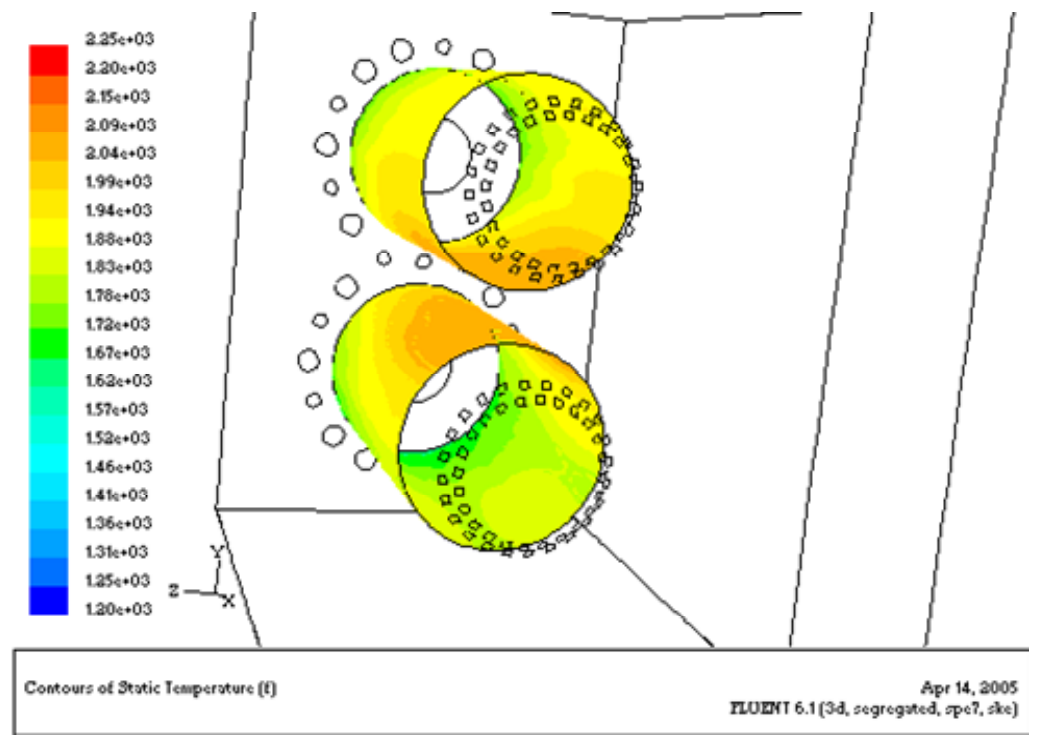

Figure 17. CFD MODEL WITH AND WITHOUT REFRACTORY FLOOR 
CFD model calculations suggested several modifications that could reduce NOx emissions by a factor of two without making gross changes to the burner geometry. The modeling results show that optimization of the current design of the burner could include the optimization of nozzles size/location in order to fit the flame to the combustion chamber, and optimization of the secondary air injection.

The model was validated based on the test results of the 20 million Btu/h prototype burner. The model parameters for flame chemistry, turbulence and mesh were fit in order to provide an agreement with measured profiles of temperature and concentrations of $\mathrm{CO}_{2}, \mathrm{O}_{2}$, and $\mathrm{THC}$ in the flame.

The results of the CFD modeling were applied to the design of the 174 million Btu/h industrial prototype burner, which resulted in a faster transition from initial installation to demonstration of performance.

\section{Field Testing}

The emissions equipment used for data collection was the same used during baseline testing. In addition, a data acquisition system (DAS) was employed to streamline the measurement process. The DAS was slightly limited due to the age of the existing burner controls, but recorded flue gas emissions from the continuous emission monitors, windbox pressure, boiler stack temperature, ambient boiler room temperature, COG venturi pressure drop, natural gas flow rate, total combustion air flow rate, and combustion air flow rate at the top and bottom secondary air ducts.

The flow rates for COG, natural gas, and total air flow were measured with the existing flow meters used during baseline testing. Two new mass flow meters were installed to measure combustion air flow rate for the top and bottom secondary air ducts. The pressures at the secondary air ducts, windbox, COG manifold, and natural gas manifold were measured with manometers and manually recorded. The draft pressure was measured with a transducer that also controlled the induced blower speed to maintain a balanced draft.

Burner characterization was initiated in March 2005 with natural gas as the main fuel. Burner performance during initial testing is represented graphically in Figure 18. NOx emissions 


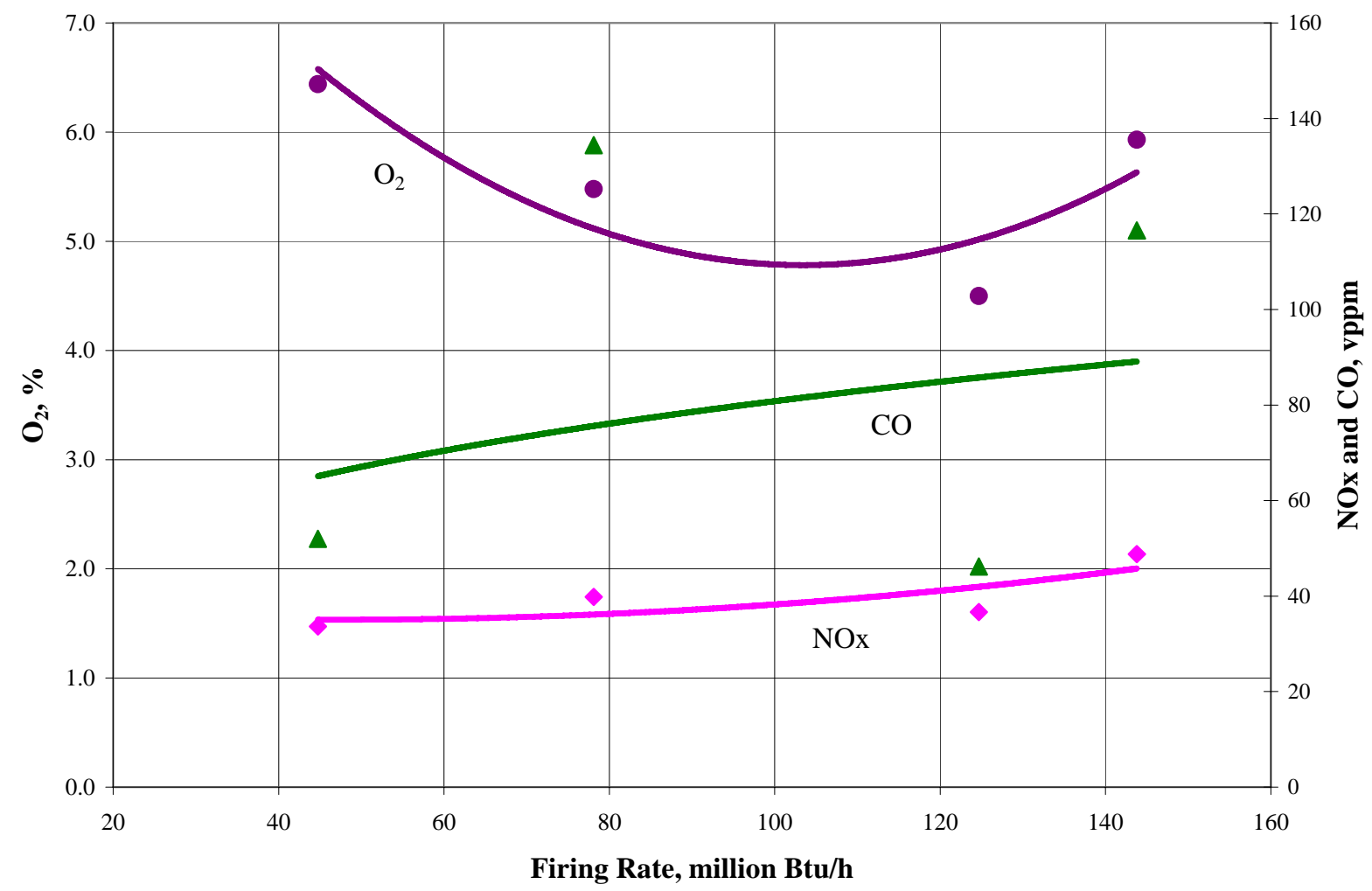

Figure 18. INITIAL DATA FIRING NATURAL GAS 
were relatively stable as firing rate increased over the range. At low fire; 45 million Btu/h, NOx emissions where $33 \mathrm{vppm}$ and increased at full load; $144 \mathrm{million}$ Btu/h, to $49 \mathrm{vppm}$. CO emissions fluctuated with the oxygen content and remained below $135 \mathrm{vppm}$ during all tests. The boiler was operated in manual mode and the oxygen content was set by the operator. The boiler's maximum output was not achieved due to a limitation dictated by the host site natural gas supply. All test data presented in this report is with both pilots off during main flame operation. The pilots for main flame ignition could be operated as intermittent or interrupted.

The ammonia scrubber for COG cleanup was in the process of being rebuilt during this test campaign. As a result, the ammonia content in the COG was higher than expected and in turn raised the fuel bound NOx output from the burner. Samples of COG were collected on May 23, 2005 to determine ammonia and hydrogen cyanide content. As during baseline testing, all samples collected for the ammonia analysis were collected in $0.1 \mathrm{~N}$ sulfuric acid; whereas, the hydrogen cyanide samples were collected on soda lime. These results are shown in Table 8.

Table 8. COG Analysis May 2005

\begin{tabular}{|l|l|l|}
\hline Sample description & $\begin{array}{l}\text { Hydrogen Cyanide } \\
\text { Content, } \\
\text { vppm }\end{array}$ & $\begin{array}{l}\text { Ammonia Content, } \\
\text { vppm }\end{array}$ \\
\hline Process line & 236 & 8426 \\
\hline
\end{tabular}

Both the hydrogen cyanide and the ammonia content had increased dramatically. Compared to the analysis performed during baseline testing the hydrogen cyanide content increased about 4 times and the ammonia content increased 15 times. Multiple COG samples were collected to confirm the accuracy of the results. NOx emissions were reduced about $50 \%$ when compared to baseline testing. Despite the additional fuel bound component in the fuel the FIR burner produced relatively low NOx emissions. The emissions data collected during May are shown in Figure 19. At low fire; 52 million Btu/h, NOx emissions where $266 \mathrm{vppm}$ and increased at full load; 148 million Btu/h, to $315 \mathrm{vppm}$. CO emissions fluctuated with the oxygen content but remained below $22 \mathrm{vppm}$ during all tests. CO emissions were reduced about $86 \%$ when compared to baseline testing. The boiler was operated in manual mode and the oxygen content was set by the boiler operator. 


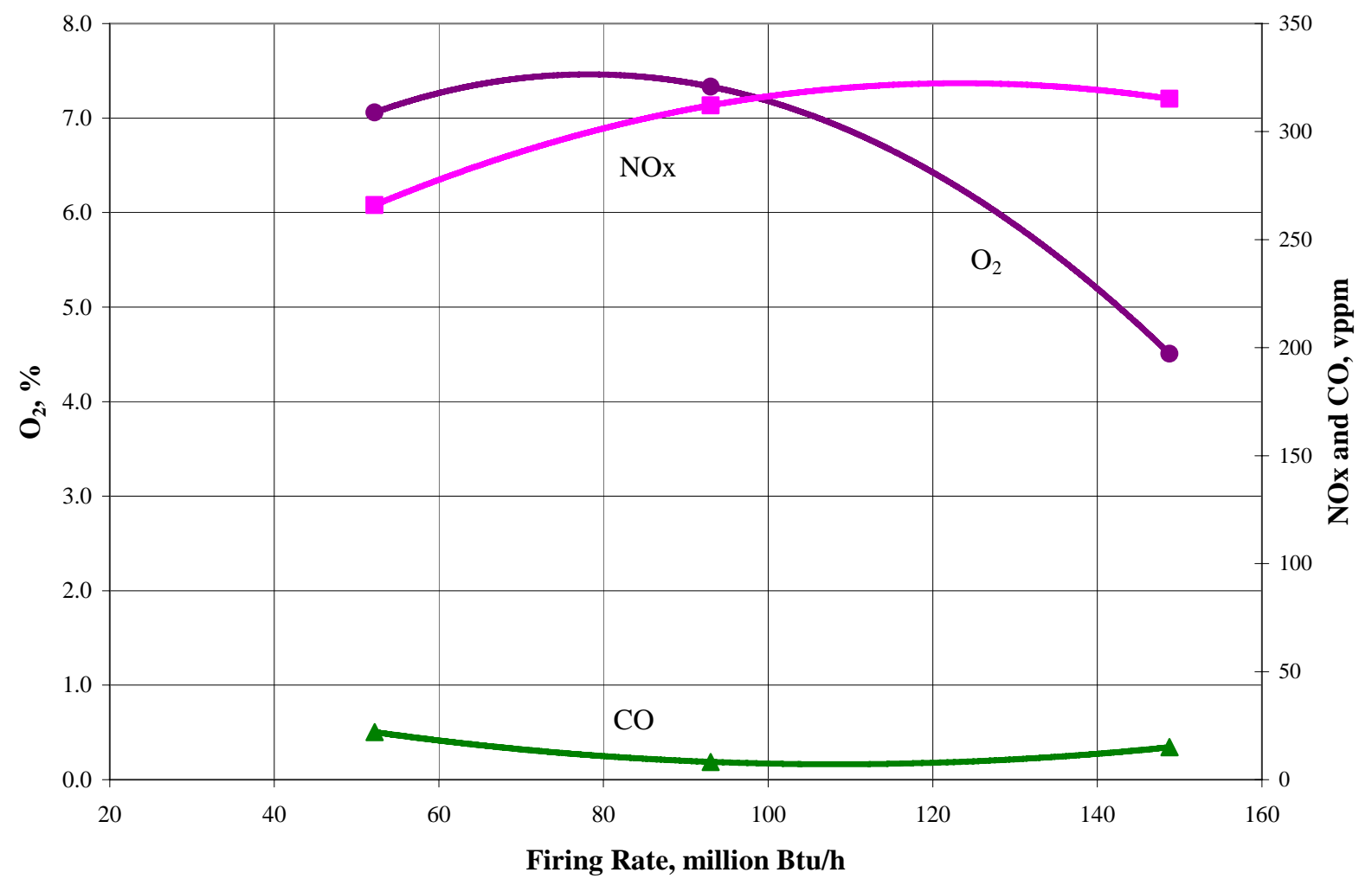

Figure 19. FIR BURNER EMISSIONS FIRING COG SCRUBBER OFF-LINE 
During FIR burner characterization, it was observed that the pressure drop in the secondary air ducts were higher than anticipated. As a result, the opposed blade damper on the main combustion air duct was practically closed in order to force more air towards the secondary air ducts. The damper was oversized. This would not have been an issue if there had been slightly more reserve from the combustion air blower. Instead, the blower was operating at peak capacity. Two modifications were implemented to reduce the pressure loss encountered in the secondary air ducts. The branch tee that supplies air to the secondary was replaced with a long radius elbow as shown in Figure 20. In addition, inlet scoops were installed internal to the main duct at the location where secondary air is diverted from the main combustion air duct. Both modifications results in a reduced pressure loss of approximately 3.5 to 4.0 in wc at full load conditions.

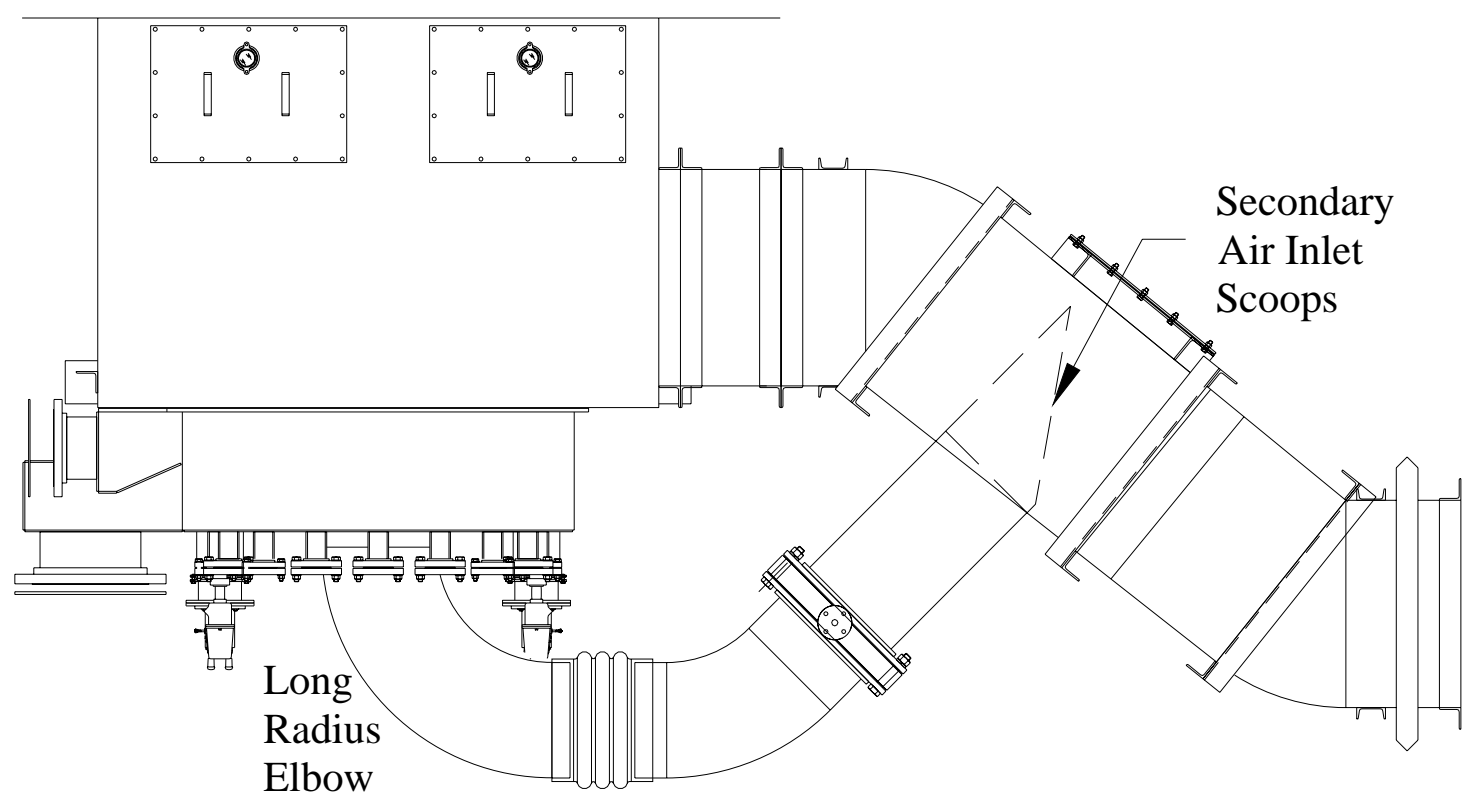

Figure 20. MODIFICATIONS TO SECONDARY AIR DUCT 
During March 2006, the construction of the scrubber for COG cleanup was completed and the system was operating. Burner characterization resume in early April. The burner performance was characterized on both COG and natural gas. COG samples were collected on April 11, 2006 to determine ammonia and hydrogen cyanide content. As conducted during baseline testing and May 2005 tests, all samples collected for the ammonia analysis were collected in 0.1 $\mathrm{N}$ sulfuric acid; whereas, the hydrogen cyanide samples were collected on soda lime. The COG ammonia content from the newly constructed scrubber had shown a dramatic decrease; however, the hydrogen cyanide content increased significantly. Multiple samples were analyzed to verify the accuracy of the results. Table 9 shows the results from the April 11, 2006 analysis.

Table 9. COG Analysis April 2006

\begin{tabular}{|l|l|l|}
\hline Sample description & $\begin{array}{l}\text { Hydrogen Cyanide } \\
\text { Content, } \\
\text { vppm }\end{array}$ & $\begin{array}{l}\text { Ammonia Content, } \\
\text { vppm }\end{array}$ \\
\hline Process line & 4214 & 43.9 \\
\hline
\end{tabular}

Burner performance data from the test campaign with the newly constructed scrubber on-line are shown in Figure 21. The values for both $\mathrm{NOx}$ and $\mathrm{O}_{2}$ were high at lower firing rates. High oxygen values can be attributed to the fixed location of the opposed blade damper in the main combustion air duct. The corresponding pressure drop curves between the primary and secondary air ducts were favoring the primary; which directed additional combustion air towards the primary zone as the firing rate decreased. This effect was overcome at higher firing rates. Since the primary fuel at the site would be COG, the burner was setup with a greater turndown. Adding a control motor to the opposed blade damper would allow the primary air to be modulated across the firing range. At low fire conditions the damper would be further closed and result in a lower oxygen set point. At full load; $167 \mathrm{million}$ Btu/h, NOx emissions were relatively low at $169 \mathrm{vppm}$. This represents a $30 \%$ reduction compared to baseline emissions not accounting for the higher hydrogen cyanide content in the COG. CO emissions remained below $20 \mathrm{vppm}$ and were stable across the firing range. This represents a $68 \%$ reduction compared to baseline $\mathrm{CO}$ emissions. Figure 22 compares the bottom burner flame firing natural gas and COG at approximately $75 \%$ of full firing rate. 


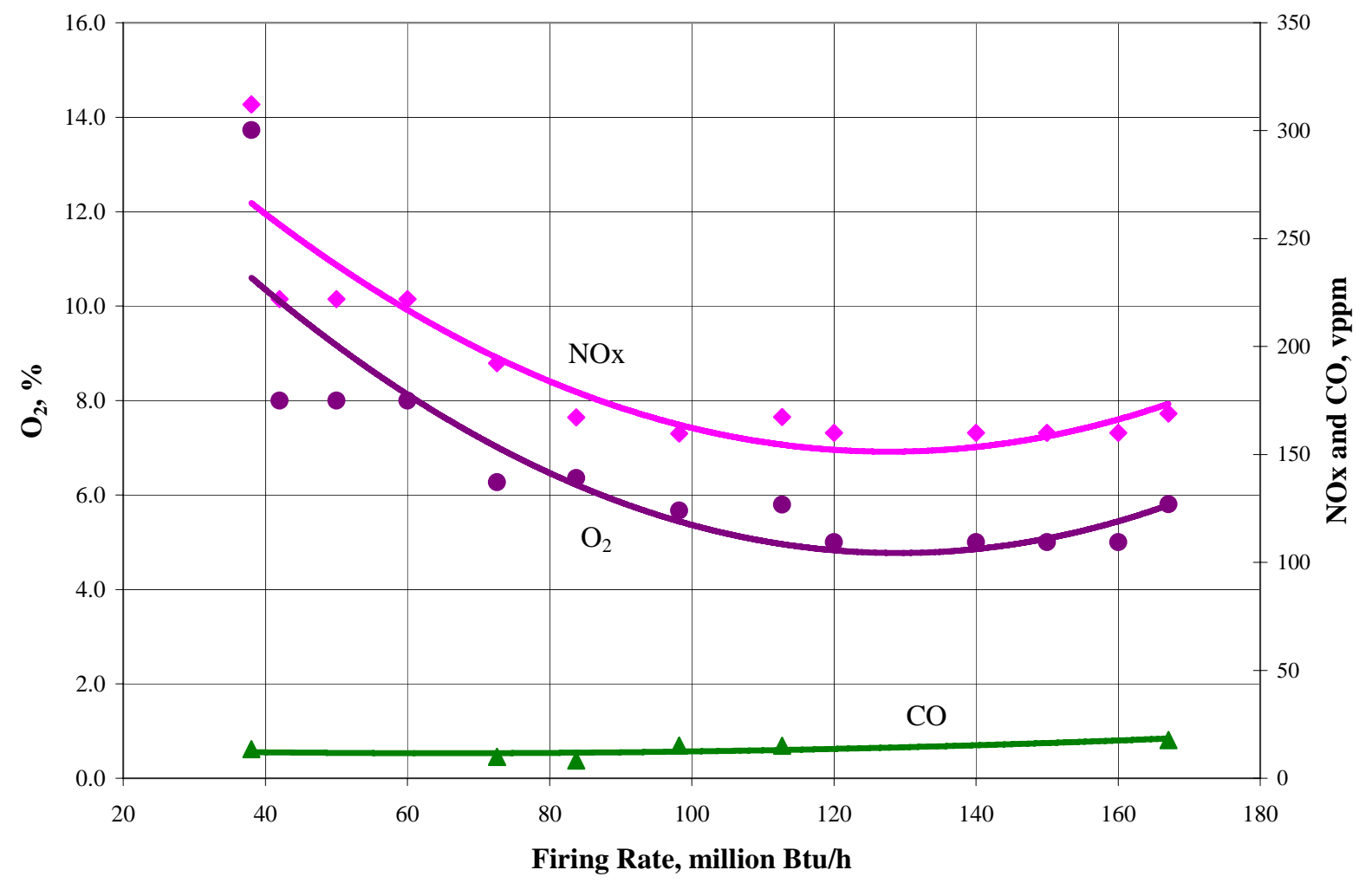

Figure 21. FIR BURNER EMISSIONS FIRING COG SCRUBBER ON-LINE 


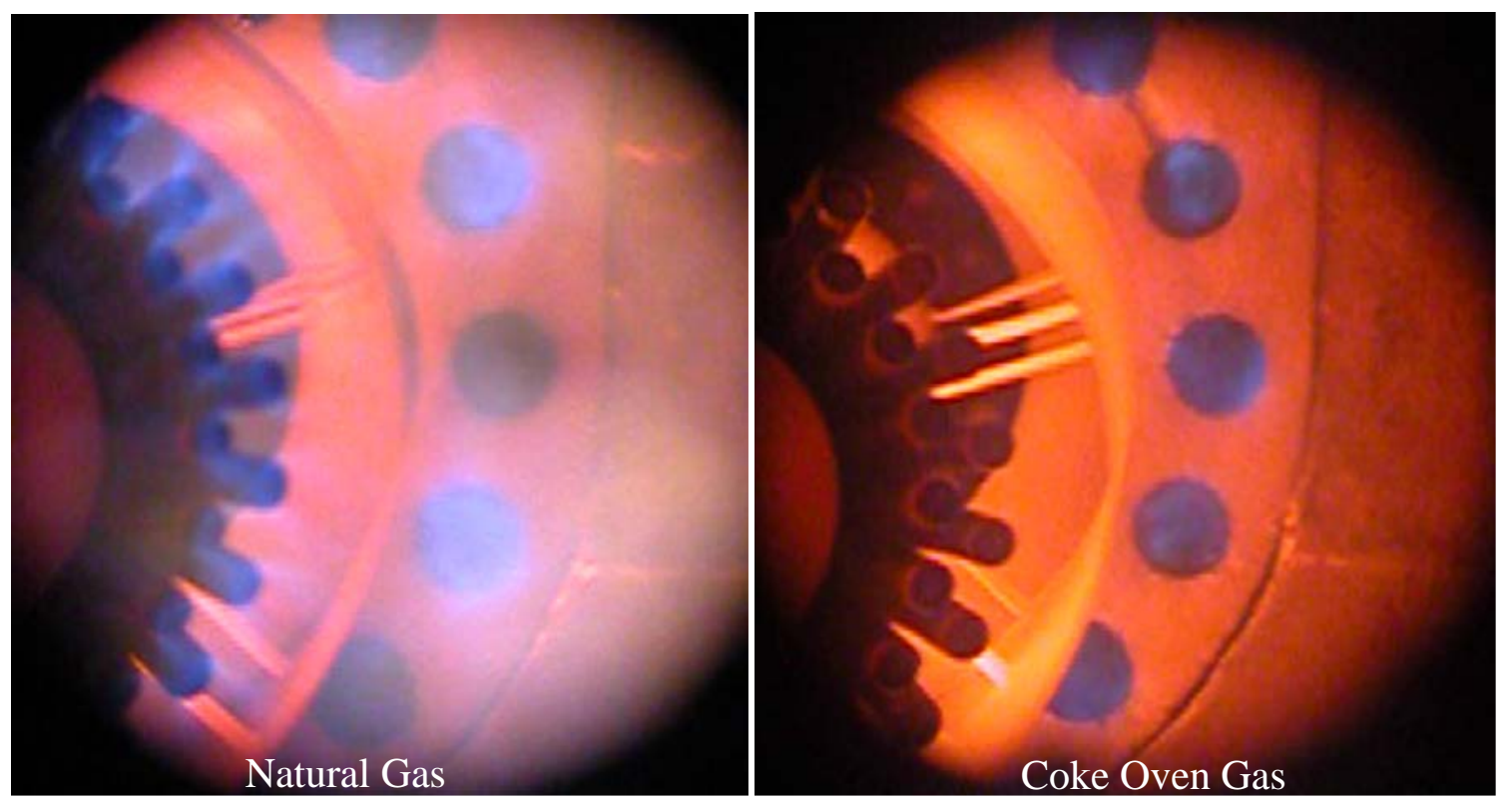

Figure 22. FIR BURNER FLAME AT 75\% LOAD

The 174 million Btu/h industrial prototype burner was placed in continuous operation April 14, 2006. Plant personnel were trained in control and operation of the burner. Morning rounds on May 5, 2006 confirmed normal burner operation. The entire coke-oven gas plant experienced a power outage the evening of May $5^{\text {th }}$ and the burner was brought back on-line May 6, 2006.

On May 8, 2006 GTI personnel visited the coke-oven gas boiler site and found that the burner had experienced a component failure. The burner had drooped within the combustion chamber yet it was still operating. Operational data was collected before the burner was shut down. Flow discrepancies were noted with the primary combustion air output signal when compared to the set points programmed into the controller. Upon inspection it appears that the secondary air tube had relaxed causing the burner components to droop towards the boiler floor. The Team has not experienced a component failure of this nature in any other burner or field demonstration to date. 
The Project Team identified several possible causes that could have lead to the component failure. A list of engineering improvements was generated to prevent the occurrence from happening again. Engineering drawings were marked for revision. A contractor Scope of Work was generated to identify the level of work required. Several installation contractors were selected to provide an estimate for the repair. The meeting with installation contractors was delayed for several weeks while the coke-oven gas site addressed emergency repairs to another boiler. The FIR burner was actually fired in its present state to generate steam while emergency repairs were conducted on another boiler. A meeting with the installation contractors was held June 27, 2006 at the site. The work effort was outlined to the contractors and the boiler combustion chamber was inspected.

A series of cold flow tests were conducted with the opposed blade damper in the main combustion air duct. The present configuration had seven opposing blades that modulate the flow. The quantity of primary combustion air required dictated the position of the blades to be near closed. Any resulting change to the blade position resulted in a large change in primary air flow. A test series was conducted with four of the blades fixed in their closed position. The remaining three blades were free to modulate the air flow. Data collected over the full operating range confirmed the enhance control of primary air supply while maintaining sufficient combustion air at full load.

Estimates were obtained for the required modifications, repair, installation, and start up however the Project Team could not secure additional funding to complete the work effort.

\section{CONCLUSIONS}

The GTI/Hamworthy Peabody Team has demonstrated a novel low-emission FIR burner for application to boilers in the steel industry. The burner can fire natural gas and coke-oven gas (COG).

During laboratory evaluation on a 20 million Btu/h prototype burner both natural gas and simulated COG were tested. Additional tests were conducted, doping the simulated COG with ammonia. Representative ammonia concentrations, as documented in the steel industry, range from 200 to $500 \mathrm{vppm}$. Ammonia concentrations were varied in the laboratory evaluation from zero to $1000 \mathrm{vppm}$, clearly extending the range encountered in industry. In industry, a present 
state-of-the-art burner operating with $500 \mathrm{vppm}$ ammonia in the fuel will produce about $280 \mathrm{vppm}$ NOx. The laboratory data revealed a direct relationship between NOx emissions and ammonia concentration in the fuel. In addition, NOx emissions increase as the PSR increases.

NOx emissions ranged from 50 to $75 \mathrm{vppm}$ when the laboratory burner was operated with $500 \mathrm{vppm}$ ammonia in the fuel. This, conservatively, is $75 \%$ less than state-of-the-art burner performance. When the burner was operated with $200 \mathrm{vppm}$ ammonia in the fuel, the NOx emissions range from 30 to $45 \mathrm{vppm}-84 \%$ less than with present burner technology.

$\mathrm{CO}$ and THC emissions were stable across the load range. The emissions were $<50 \mathrm{vppm}$ for the majority of tests. At deep-staging conditions (PSR less than 0.72) CO emissions rose slightly.

The prototype FIR burner has proven to operate satisfactory on the 20 million Btu/h watertube boiler at GTI. Acceptable burner performance was obtained when firing natural gas and simulated coke-oven gas doped with ammonia.

During field evaluation on a 174 million Btu/h industrial prototype burner both natural gas and actual COG from on-site generation were tested. Despite the elevated fuel-bound nitrogen content in the COG throughout the test program, the FIR burner showed an improvement over baseline emissions. At full load; 167 million Btu/h, NOx emissions were relatively low at $169 \mathrm{vppm}$. This represents a 30\% reduction compared to baseline emissions not accounting for the higher hydrogen cyanide content in the COG. CO emissions remained below $20 \mathrm{vppm}$ and were stable across the firing range. This represents a $68 \%$ reduction compared to baseline CO emissions. Low fire emission performance would be improved through modification of the main combustion air opposed blade damper with four blades fixed in their closed position. This behavior is shown in Figure 21 where the $\mathrm{O}_{2}$ and NOx are constant through the firing range until the firing rate goes below $40 \%$ and then they both raise significantly. When firing natural gas, emissions were stable as firing rate increased over the range. At low fire; 45 million Btu/h, NOx emissions where $33 \mathrm{vppm}$ and increased at full load; $144 \mathrm{million} \mathrm{Btu/h}$, to $49 \mathrm{vppm}$. CO emissions fluctuated with the oxygen content and remained below $135 \mathrm{vppm}$ during all tests. The boiler was operated in manual mode and the oxygen content was set by the operator. The boiler's maximum output was not achieved due to a limitation dictated by the host site natural gas supply. 
The ammonia and hydrogen cyanide content in the COG proved to be higher than what is typically encountered in the steel industry. Compared to the analysis performed during baseline testing the hydrogen cyanide content increased about 4 times and the ammonia content increased 15 times. Even after, the construction of the scrubber for COG cleanup was completed and the system was operating the hydrogen cyanide content remained 15 times higher than encountered during baseline testing. The accuracy of the results was confirmed with multiple samples.

The influence of ammonia in the fuel, and its influence on NOx production, was studied extensively in the laboratory testing performed at GTI. Observations from those tests demonstrated a linear relationship between ammonia content and NOx produced by the burner. Figure 23 exhibits that relationship between the 20 million Btu/h laboratory prototype burner and the 174 million Btu/h industrial prototype burner at a primary stoichiometric ratio of 0.90 . In this figure, a line has been drawn through the two sets of points and the slope for the laboratory burner is steeper than for the field burner. The data suggests that the relationship is not linear when the fuel-bound nitrogen content is at extreme levels, but instead, it is a curve that flattens out as the ammonia concentration increases. There may also be a larger influence in the thermal NOx mechanism for the 174 million Btu/h industrial prototype burner. This is likely the case, since the NOx values encountered firing natural gas were higher for the 174 million Btu/h industrial prototype burner than the 20 million Btu/h laboratory prototype burner.

The data from both the laboratory and field burners could provide an approximation of the fuel bound NOx contribution via the fuel-bound nitrogen compounds in the fuel. The approximation would allow a comparison to baseline tests at the lower fuel-bound nitrogen content in the fuel. Linear extrapolation from the test points of the 174 million Btu/h industrial prototype burner down to $151 \mathrm{vppm}$ suggest that the burner would produce a NOx content of approximately $85 \mathrm{vppm}$. This is a $63 \%$ reduction compared to baseline data. However, compared to the 20 million Btu/h laboratory prototype burner, there is an increase in NOx at $151 \mathrm{vppm}$. Using the linear relationship of the 20 million Btu/h laboratory prototype burner at comparable levels of nitrogen compounds, the NOx formed from combustion would be approximately $30 \mathrm{vppm}$. This could point to a greater influence of the thermal NOx mechanism for the 174 million Btu/h industrial prototype burner. 


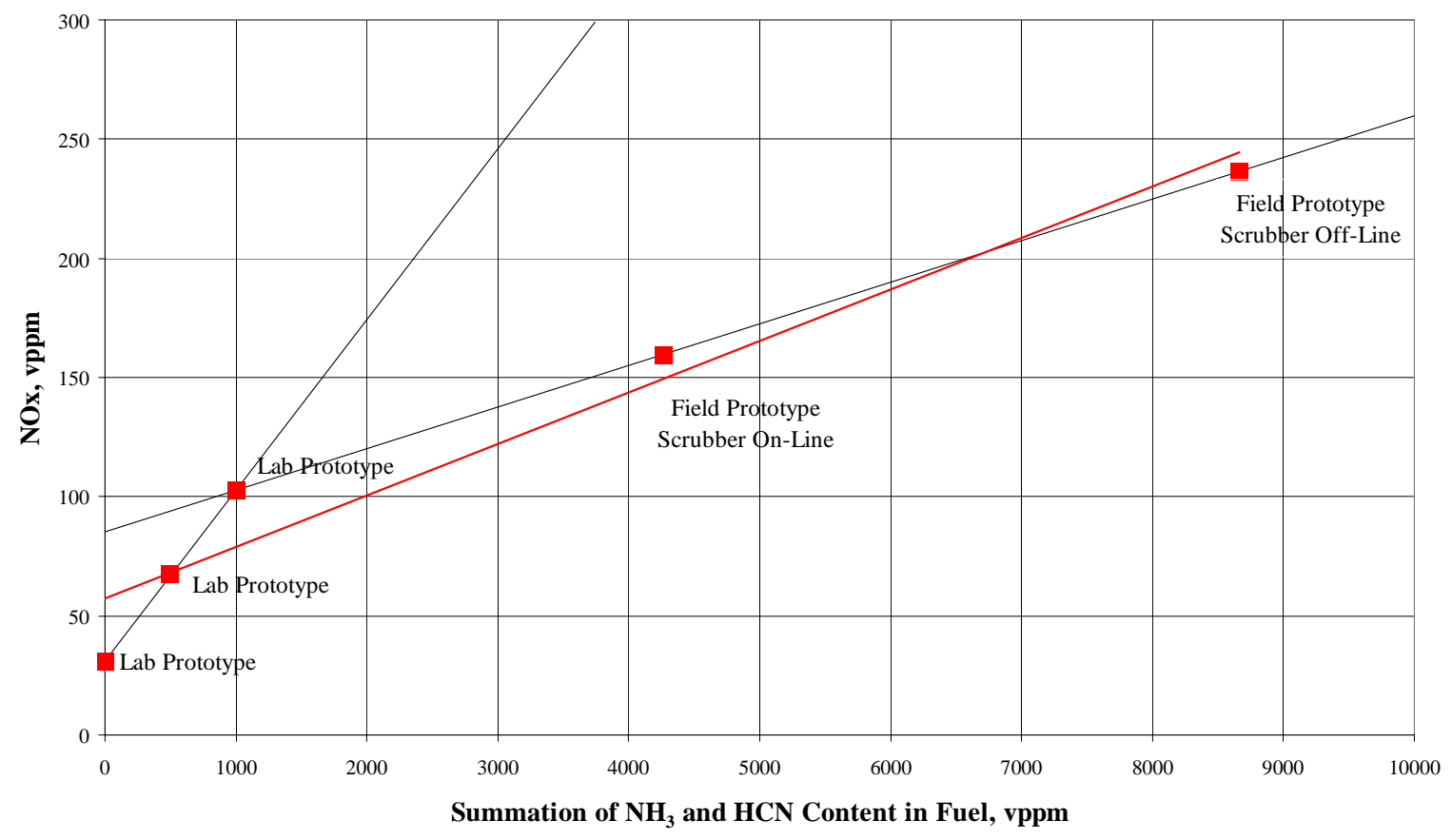

Figure 23. NOX COMPARISON AS IT RELATES TO NITROGEN COMPOUNDS IN COG 
The design of the 174 million Btu/h industrial prototype burner was scaled up approximately 9 times from the 20 million Btu/h laboratory burner in a multi-burner arrangement. The scaled-up version of the burner proved to be confined within the combustion chamber. To reduce the overall dimensions, the primary nozzles located between the top and bottom burners were combined. As a result, the recirculation inserts were closer together. In addition, the floor of the combustion chamber was lined with refractory tile. The additional radiation may have played a role in raising the flame temperature as shown in the modeling effort. In fact, physical observations of the flame and the glow of the recirculation insert indicated the placement of the primary nozzles resulted in an increased flame temperature.

Gratitude and appreciation are given to the U.S. Department of Energy, GRI, and Gas Technology Institute Sustaining Membership Program for funding this project. Special thanks are also extended to the coke-oven gas boiler site for the use of their facility during this project and to Mr. Larry Emerick and Mr. Vincent Gard for their innovation and hard work through this work effort.

\section{RECOMMENDATIONS}

Industrial boilers that fire byproduct fuels represent a significant market share in the steel industry. If these combustion systems were not able to meet the more stringent future emissions standards, the alternative would be to use electricity or post combustion NOx reduction techniques. The use of electric energy would, however, in most cases, result in a number of drawbacks for the end user: higher energy costs and expensive equipment modifications or replacements, as well as the country: overall increase in pollution levels resulting from the use of less clean fuels during electricity generation and an increase in the overall energy consumption because of the relatively low fuel to electricity conversion efficiencies. Similarly, the use of post combustion techniques would substantially increase the capital costs and energy use because of the energy required for the operation of the post combustion equipment and to produce and transport the necessary chemical reagents. Most importantly, byproduct fuels are "free" and "available." The potential benefits of the work effort are to provide a cost effective means for meeting the local emission requirements without increasing the overall energy requirements and fuel consumption. 
At the present time, state-of-the-art advanced combustion systems that have demonstrated lowNOx capabilities firing byproduct fuels in the steel industry are non-existent. Additionally, stringent restrictions are anticipated for NOx and CO emissions. There is a need for costeffective low-emission burners with which to retrofit existing boilers to meet the expected environmental restrictions, without loss of boiler capacity or thermal efficiency.

\section{REFERENCES}

1. "Method for Two-Stage Combustion Utilizing Forced Internal Recirculation," M. J. Khinkis, H. A. Abbasi and D. F. Cygan, U.S. Patent No. 5,350,293 September 27, 1994.

2. Downloaded from the American Coke and Coal Chemicals Institute website; www.acci.org, May 9, 2005.

3. Downloaded from the American Coke and Coal Chemicals Institute website; www.acci.org, May 9, 2005.

4. Environmental Protection Agency (EPA). Summary of NOx Control Technologies and their Availability and Extent of Application, EPA-450/3-92-004. Research Triangle Park, North Carolina. U.S. Environmental Protection Agency Office of Air and Radiation 1992.

5. Steel Industry Technology Roadmap.

6. D. F. Cygan, J. K. Rabovitser, R. A. Knight and J. Pratapas 2002. "Forced Internal Recirculation (FIR) Burner Technology for Ultra-Low-NOx Boiler Performance," presented at Natural Gas Technologies: What's New \& What's Next, Orlando, Florida, Sept-Oct, 2002. 
APPENDIX 
Table 10. Operating U.S. Coke Plants (as of March 18, 2005)

\begin{tabular}{|c|c|c|}
\hline State & Company & City \\
\hline \multirow[t]{2}{*}{ Alabama } & ABC Coke (Drummond Company, Inc.) $)^{1}$ & Tarrant \\
\hline & Sloss Industries Corp. ${ }^{1}$ & Birmingham \\
\hline Illinois & U.S. Steel ${ }^{2}$ & Granite City \\
\hline \multirow[t]{4}{*}{ Indiana } & Indiana Harbor Coke Company ${ }^{1,3}$ & East Chicago \\
\hline & \begin{tabular}{|l|l} 
International Steel Group (ISG Coke) ${ }^{2}$ \\
\end{tabular} & Burns Harbor \\
\hline & Citizens Gas \& Coke Utility ${ }^{1}$ & Indianapolis \\
\hline & U.S. Steel ${ }^{2}$ & Gary \\
\hline Kentucky & AK Steel Corp. ${ }^{2}$ & Ashland \\
\hline Michigan & 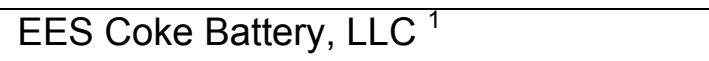 & Ecorse \\
\hline New York & 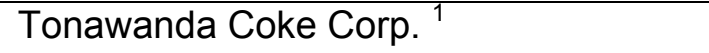 & Tonawanda \\
\hline \multirow[t]{3}{*}{ Ohio } & AK Steel Corp. $^{2}$ & Middletown \\
\hline & International Steel Group (ISG Coke) ${ }^{2}$ & Warren \\
\hline & Sun Coke Co. ${ }^{1,3}$ & Haverhill \\
\hline \multirow[t]{4}{*}{ Pennsylvania } & Erie Coke Corp. $^{1}$ & Erie \\
\hline & Koppers, Inc. $^{1}$ & Monessen \\
\hline & Shenango, Inc. ${ }^{1}$ & Pittsburgh \\
\hline & U.S. Steel ${ }^{2}$ & Clairton \\
\hline Virginia & Jewell Coke and Coal $^{1,3}$ & Vansant \\
\hline Western Virginia & Wheeling-Pittsburgh Steel Corp. ${ }^{2}$ & Follansbee \\
\hline
\end{tabular}


Table 11. Basis of Avoided Natural Gas

\begin{tabular}{|ll|}
\hline Total steel production, million ton/year $^{\text {a }}$ & 100 \\
Energy consumption rate, million Btu/ton & 15.0 \\
Total energy used in U.S. steel industry, trillion Btu/year & 1,500 \\
Boiler burner market, units & 250 \\
Average burner size, million Btu/h & 100 \\
Estimated boiler market energy demand, trillion Btu/year & 219 \\
Contribution from boilers \% & 14.6 \\
\hline
\end{tabular}

Sources:

a. Steel Industry Technology Roadmap, p. 2

Table 12. Basis for Calculation of Economic Benefits

\begin{tabular}{|c|c|}
\hline Boiler burner market, units & 250 \\
\hline Range of boiler sizes used at steel industry plants, million Btu/h & $40-200$ \\
\hline Average burner size, million Btu/h & 100 \\
\hline \multicolumn{2}{|l|}{ Capital cost, \$/unit } \\
\hline Low-NOx burner (target) ${ }^{a}$ & $\$ 110,000$ \\
\hline Alternative control method $1^{\mathrm{b}}$ & $\$ 140,000$ \\
\hline Alternative control method $2^{C}$ & $\$ 200,000$ \\
\hline Fuel cost, \$/ million Btu & $\$ 1.75$ \\
\hline \multicolumn{2}{|l|}{ Annual fuel cost, \$/unit/year } \\
\hline Low-NOx burner (target) & $\$ 1,839,600$ \\
\hline Alternative control method $1^{\mathrm{b}}$ & $\$ 1,848,798$ \\
\hline Alternative control method $2^{c}$ & $\$ 1,848,798$ \\
\hline Maintenance cost, \% of capital cost & $5 \%$ \\
\hline Unit lifetime, year & 20 \\
\hline Escalation rate, \%/year & 3.0 \\
\hline
\end{tabular}


Table 13. Basis for Calculation of Energy Benefits

\begin{tabular}{|c|c|}
\hline U.S. steel production, million ton/year ${ }^{a}$ & 100 \\
\hline Energy consumption rate, million Btu/ton & 15.0 \\
\hline Total energy used in U.S. steel industry, trillion Btu/year & 1,500 \\
\hline Estimated boiler market energy demand, trillion Btu/year & 219 \\
\hline Boiler contribution to total steel industry energy demand, $\%$ & 14.6 \\
\hline \multicolumn{2}{|l|}{ Energy penalty, \% } \\
\hline Low-NOx burner (target) & no penalty \\
\hline Alternative control method $1^{\mathrm{b}}$ & 0.5 \\
\hline Alternative control method $2^{c}$ & 0.5 \\
\hline
\end{tabular}

Sources:

a. Steel Industry Technology Roadmap, p. 2

b. External FGR, designed for $65 \%$ NOx reduction

c. SNCR, designed for $65 \%$ NOx reduction

Table 14. Basis for Calculation of Environmental Benefits

\begin{tabular}{|c|c|}
\hline Total domestic NOx emissions from steelmaking, ton/year ${ }^{a}$ & 138,985 \\
\hline Percent contribution from boiler burners, $\%^{\mathrm{b}}$ & 14.6 \\
\hline $\begin{array}{l}\text { Total domestic NOx emissions from steel facility boilers, } \\
\text { ton/year }\end{array}$ & 15,288 \\
\hline \multicolumn{2}{|l|}{ NOx concentration, vppm } \\
\hline Uncontrolled boiler ${ }^{\mathrm{c}}$ & 200 \\
\hline Low-NOx burner (target) & 15 \\
\hline Alternative control method $1^{d}$ & 30 \\
\hline Alternative control method $2^{\mathrm{e}}$ & 30 \\
\hline
\end{tabular}

Sources:
a. Steel Industry Technology Roadmap, p. 118
b. Equal to energy contribution (see previous table)
c. Calculated from overall NOx per unit energy in steel industry, converted to vol/vol according to $8.385 \mathrm{scf}$ dry flue gas per $1000 \mathrm{Btu}$; typical NOx from gas-fired boilers is $80-100 \mathrm{vppm}$, but use of COG can raise to much higher levels due to residual fuel-bound nitrogen.
d. External FGR, designed for $65 \%$ NOx reduction
e. SNCR, designed for $65 \%$ NOx reduction 